\title{
Treatment of COPD: from pharmacological to instrumental therapies
}

\author{
M. Alifano*, A. Cuvelier*, A. Delage ", N. Roche+, B. Lamia\#, L.C. Molano\#, L-J. Couderc ${ }^{+, \S}$, \\ C-H. Marquette and P. Devillier ${ }^{f}$
}

$\mathbf{T}$ he two main goals of the current management of chronic obstructive pulmonary disease (COPD) are: 1) to reduce the impact of the disease on daily activities; and 2) to reduce the risk of future events (exacerbations, lung function decline and death) [1]. The first measure is obviously smoking cessation; however, we will not discuss this.

Treatment guidelines are mainly based on randomised clinical trials that include a small and highly selected fraction of the COPD population [2]. Therefore, it is questionable as to whether these evidence-based guidelines can be extrapolated to the overall COPD population in the everyday practice. Indeed, less than one in five or 10 patients with COPD could fit into inclusion or exclusion criteria commonly used in clinical trials evaluating efficacy of pharmacological treatments [2,3]. In addition, COPD is a heterogeneous disease and patients with similar forced expiratory volume in $1 \mathrm{~s}$ (FEV1) may show very different functional status, underlying lung pathology and comorbidities. For most treatments, differences in the responsiveness of COPD subgroups are not yet established and large, long clinical trials, along with high-quality meta-analyses, remain the basis of the current treatment guidelines and the evaluation of the benefit/risk ratio of the main therapeutic classes used in COPD management. However, even the large therapeutic trials may suffer from methodological limitations in the design or analysis [4].

The most important outcomes in clinical trials are patientcentred outcomes. Exacerbations, health-related quality of life and mortality are logical major outcomes in COPD trials [4]. In addition, exercise performance and lung function decline are other important targets for therapeutic intervention in COPD [5]. Lung function and biological markers reliably predicting individual response to treatments would be useful.

\footnotetext{
${ }^{*}$ Thoracic Surgery, and ${ }^{+}$Respiratory Intensive Care Medicine, Hôtel-Dieu, University of Paris Descartes, Paris, " Respiratory and Intensive Care Dept, Rouen University Hospital, and UPRES EA 3830 (IFRMP 23), Institute for Biomedical Research, University of Rouen, Rouen, "Service de Pneumologie, Oncologie Thoracique et Soins Intensifs Respiratoires, Centre Hospitalier Universitaire

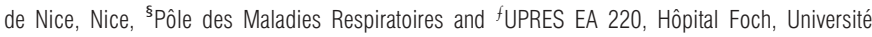
Saint-Quentin en Yvelines, Versailles, France.

CORRESPONDENCE: N. Roche, Pneumologie et Réanimation, Hôtel-Dieu, University of Paris Descartes, 1 place du Parvis de Notre-Dame, 75004, Paris, France. E-mail: nicolas.roche@ htd.aphp.fr
}

Received: Dec 03 2009; Accepted after revision: Dec 172009

PROVENANCE: Submitted article, peer reviewed.

\section{PHARMACOLOGICAL INTERVENTIONS \\ Bronchodilators}

Bronchodilators are the mainstay of the current pharmacological management of COPD. Long-acting bronchodilators reduce exacerbations and improve health-related quality of life [6-11]. The inconsistencies in the definitions or statistical analyses of exacerbations hamper comparison of efficacy data on this outcome between trials performed with different long-acting bronchodilators [4, 12]. A clinical trial has been designed to compare the effect of tiotropium and salmeterol on exacerbations and would require the inclusion of 6,800 patients in order to potentially detect a difference in efficacy between the two long-acting bronchodilators [13]. The reduction of lung function decline by bronchodilators is a matter of debate [11]. A post hoc analysis of the TORCH study suggested that salmeterol reduces the rate of decline in post-bronchodilator FEV1 versus placebo [8]. A post hoc analysis of two 1-yr trials with tiotropium versus placebo also showed an improvement in the rate of decline of FEV1 [14]. Except in patients with Global Initiative for Chronic Obstructive Lung Disease (GOLD) stage II COPD [10], tiotropium did not reduce the rate of decline of post-bronchodilator FEV1 versus the control group in the UPLIFT study [9]. However, the rate of decline in the UPLIFT control group was similar to the rate of decline in the active groups in the TORCH study (table 1). One of the main differences between these two landmark studies is that the control group in UPLIFT included patients treated with long-acting bronchodilators (72\%), inhaled corticosteroids $(74 \%)$ or a combination $(46 \%)$ whereas these treatments were obviously not permitted in the TORCH placebo group. Subgroup analysis of patients not receiving corticosteroids or long-acting bronchodilators in UPLIFT revealed a lower rate of FEV1 decline on tiotropium versus the corresponding control group, which was, therefore, similar to the TORCH placebo group. These results suggest that tiotropium could reduce lung function decline in otherwise untreated patients but is unable to add further effect on this criteria in a group of patients already receiving long-acting bronchodilators or inhaled corticosteroids. As salmeterol, fluticasone and the salmeterol/fluticasone combination [8] caused a similar effect on lung function decline, results from TORCH and UPLIFT strongly suggest that single agents (salmeterol, fluticasone and tiotropium) could similarly reduce the rate of decline versus placebo and could reach by themselves, a ceiling level explaining why combinations of these agents appear unable to provide further benefit [11]. 


\begin{tabular}{|c|c|c|c|}
\hline TABLE 1 & \multicolumn{3}{|c|}{$\begin{array}{l}\text { Annual loss in forced expiratory volume in } 1 \mathrm{~s} \\
(\mathrm{FEV} 1) \text { in the TORCH and UPLIFT trials by } \\
\text { treatment group }\end{array}$} \\
\hline Study & & Treatment arm & $\begin{array}{c}\text { Annual loss in } \\
\text { FEV } 1 \mathrm{~mL}\end{array}$ \\
\hline \multirow{4}{*}{\multicolumn{2}{|c|}{$\mathrm{TORCH}^{\#}$}} & $\begin{array}{l}\text { Salmeterol/fluticasone } \\
\text { combination }\end{array}$ & 39 \\
\hline & & Salmeterol & 42 \\
\hline & & Fluticasone & 42 \\
\hline & & Placebo & 55 \\
\hline \multirow{2}{*}{\multicolumn{2}{|c|}{ UPLIFT: whole population }} & Tiotropium & 40 \\
\hline & & Control & 42 \\
\hline \multirow{2}{*}{\multicolumn{2}{|c|}{ UPLIFT: patients with no ICS/LABA }} & Tiotropium & 40 \\
\hline & & Control & 47 \\
\hline \multicolumn{4}{|c|}{$\begin{array}{l}\text { ICS: inhaled corticosteroids; LABA: long-acting } \beta_{2} \text {-agonists. }{ }^{*}: \text { LABA or ICS } \\
\text { were not authorised in the TORCH trial; } \because \text { : ICS and LABA were authorised as } \\
\text { concomitant treatments in the UPLIFT trial. Data taken from }[8,9] .\end{array}$} \\
\hline
\end{tabular}

Mortality was the primary outcome in $\mathrm{TORCH}$ and a secondary outcome in UPLIFT. In TORCH, a statistical significance was not observed, whereas it was found at the end of the protocol-defined treatment in UPLIFT, where the follow-up of mortality status was virtually complete [15]. However, the impact of salmeterol and tiotropium on mortality appears numerically similar and also similar to the impact observed with the salmeterol/fluticasone combination [11]. A factorial analysis suggested that the effect on mortality observed with the combination is entirely due to salmeterol, but the validity of this post hoc analysis has been recently challenged [12].

In addition, long-acting bronchodilators decrease lung hyperinflation at rest (reduction in functional residual capacity and increase in inspiratory capacity) and during exercise with an associated increase in exercise endurance time versus placebo $[16,17]$.

\section{Inhaled corticosteroids}

The role of inhaled corticosteroids in long-term treatment is still a matter of debate in COPD $[18,19]$. Inhaled corticosteroids by themselves do not impact on mortality but may reduce lung function decline $[7,8]$. The reduction in lung function decline in a post hoc analysis of the TORCH trial was similar to that observed with the long-acting bronchodilators and the salmeterol/fluticasone combination, suggesting no further benefit of the addition of inhaled corticosteroids to long-acting bronchodilators. As a whole, inhaled corticosteroids could reduce the rate of COPD exacerbations in moderate-to-severe patients [20, 21]. Combination of long-acting bronchodilators and inhaled corticosteroids did not significantly decrease the risk of exacerbations (except for moderate exacerbations) compared with long-acting bronchodilators or long-acting antimuscarinic (LAMA) monotherapy in COPD patients but it might be effective on this criterion in patients with an FEV1 $\leqslant 40 \%$ [21-23].

In the salmeterol/fluticasone combination, fluticasone contributes to the sustained reduction in lung hyperinflation over
$12 \mathrm{~h}$ [24]. In agreement with these data, other studies had previously found that lung hyperinflation improved after treatment with inhaled beclomethasone or fluticasone $[25,26]$.

Patients with COPD are at an increased risk for pneumonia and, when hospitalised for pneumonia, exhibit higher mortality than patients without COPD. In a post hoc analysis of the TORCH study, after adjusting for time on treatment, a greater rate of pneumonia was reported in the two treatment arms with fluticasone compared with salmeterol and placebo. For patients treated with salmeterol/fluticasone combination, a $64 \%$ increase in the risk of pneumonia at any time within 3 yrs of the trial was found, with a similar result being reported for patients treated with fluticasone alone. It was estimated that there would be one extra case of pneumonia for every 31 patients receiving salmeterol/fluticasone combination treatment over 1 yr [27]. No increase in pneumonia deaths with the combination treatment was observed. It was concluded that healthcare providers should remain vigilant for the possible development of pneumonia as a complication in COPD patients receiving these therapies [27]. Risks factors for pneumonia in multivariate analysis were advancing age ( $\geqslant 55 \mathrm{yrs}$ ), poor lung function (FEV1 $<50 \%$ predicted), body mass index (BMI) $<25 \mathrm{~kg} \cdot \mathrm{m}^{2}$ and a history of COPD exacerbations in the year prior to the study. In a recent metaanalysis of studies conducted with budesonide in COPD, the two most important clinical determinants of pneumonia were also increasing age and reduced lung function; however, budesonide does not increase the risk of pneumonia versus control regimen (formoterol or placebo) [28]. Another metaanalysis indicated an excess risk of pneumonia in patients with COPD treated with inhaled corticosteroids but also suggested that this increased risk was mainly restricted to patients who received doses of inhaled corticosteroids of $>1,000 \mu \mathrm{g} \cdot \mathrm{day}^{-1}$ beclometasone or equivalent [29]. However, a minority of patients were treated with less a dose of inhaled corticosteroids of $<1,000 \mu \mathrm{g} \cdot \mathrm{day}^{-1}$. The trials were heterogeneous in terms of study drug and duration and the meta-analysis of budenoside trials did not support this assumption. It should be noted that, in contrast to asthma, the equivalence of doses between inhaled corticosteroids has not been established in COPD and that phase II studies have not been conducted to define the dose relationship of the benefit/risk ratio of corticosteroids used alone or in combination with long-acting bronchodilators in COPD.

Finally, recent evidence suggest a benefit of the triple therapy with long-acting bronchodilators, LAMA and corticoids over long-acting bronchodilators on inspiratory capacity (which is correlated with improvements in exercise capacity) and on the reduction of severe exacerbations in moderate to severe patients [30-32].

\section{Theophylline}

It should be noted that $28 \%$ of the patients recruited in the UPLIFT study were receiving theophylline. In at least one study, theophyline associated with salmeterol has been reported to improve pulmonary function, dyspnoea and quality of life, as well as to reduce exacerbations [33]. Theophylline at doses within the therapeutic range is a weak bronchodilator and a weak phosphodiesterase inhibitor but 
can potentiate in vitro and in vivo the anti-inflammatory actions of glucocorticoids [34, 35].

\section{Phosphodiesterase-4 inhibitors}

Roflumilast is the first specific inhibitor of phosphodiesterase- 4 in the process of being marketed in COPD to treat severe patients with bronchitic symptoms and a history of exacerbations. In recently published trials, roflumilast modestly improved lung function and mainly reduced the rate of moderate to severe exacerbations independently of concomitant use of long-acting bronchodilators [36, 37]. Other clinical studies are required to clarify the place of this agent in the range of drugs available for COPD [38].

\section{Integrated care}

Because COPD is a complex, multi-domain disease, integrated care programmes are considered essential to provide the best care possible [39]. The precise structure of this type of programmes is not yet universally defined but most probably should include education (improving the inhaler technique as well as adherence to therapy) and a programme to stimulate regular physical activity, as well as the measures aimed at improving the coordination among levels of care or the responsiveness of care that may allow earlier recognition and treatment of exacerbations [40-44]. Underuse, overuse and improper use are the most common causes of poor adherence to COPD therapy. On average, $40-60 \%$ of patients with COPD adhere to the prescribed regimen and only one out of 10 patients with a metered dose inhaler performs all essential steps of device handling and drug inhalation correctly [40]. A strong association between increased adherence and improved all-cause mortality and reduction in hospital admission, independent of study treatment, has been reported in the TORCH study [45]. New bronchodilators, either ultra-longacting $\beta_{2}$-agonists such as indacaterol or long-acting antimuscarinic agents administered on a once daily basis, may improve compliance since this regimen is preferred by most patients [46]. Some of these new bronchodilators are also developed as combinations of either an ultra-long-acting $\beta_{2}$-agonists and a long-acting antimuscarinic or an ultra-long-acting $\beta_{2}$-agonists and a corticosteroid.

Regular physical activity has been shown to improve functional status and to reduce the risk of hospitalisation and mortality in COPD [42-44]. Telemedicine, supported by the European Commission and the UK government, seems ideally suited to enable real-time remote monitoring and management of COPD patients from their homes [47].

\section{Economic aspects of COPD pharmacological treatments}

The global COPD market in Europe is valued at approximately $€ 1.5$ billion [48]. This growing market is becoming a major concern in decision making about pricing and reimbursement for the stakeholders in the healthcare systems. Available treatments for COPD are mainly symptomatic, and the nearterm pipeline for COPD is mainly constituted by improved versions of currently used agents, alone or in combinations. For a new drug, it is necessary to determine whether the increase in cost is justified by the resultant improvement in patient-centred outcomes.
However, new pharmacotherapy in COPD has commonly limited additional efficacy versus their comparator as evaluated through the key clinical outcomes recommended by the European Agency for the Evaluation of Medicinal Products (EMEA). These clinical outcomes, for which the minimal clinically important difference is not always definitely established and which weakly reflect patient-related outcomes [49], are a major issue for the development of new drugs in COPD. The main criteria for drug development in COPD are about to be reconsidered by the EMEA [50]. In addition, the demonstration of product value during drug development faces the limitations of clinical trial designs, which may lead to an underestimation of costs compared with what would occur in a more naturalistic setting, especially considering the small and highly selected fraction of the COPD patient population included in these trials $[2,51]$. Treatment guidelines in COPD are mainly based on evidence from the clinical trials conducted by the pharmaceutical industry. Deviation from these guidelines frequently occurs in general practice, resulting in extra costs that could extend to more than $€ 500$ per patient per year in patients with moderate COPD [11]. The economic evaluation for the decision to include a new treatment into the reimbursed package of a health insurer requires the use of final outcomes, such as life-years gained, improvement in generic quality of life and quality-associated life years (QALYs).

The cost-effectiveness of a new drug can only be assessed with regard to the maximum that decision makers are willing to pay for an exacerbation-free month, a QALY or another unit of effect. However, this information is not known in European countries except the UK. In a recent study, the analysis of the economic data from the TORCH study suggested that, based on costs for medication and primary and secondary care resources, the trial-wide point estimate for the cost per QALY compared with placebo was $\$ 43,600$ for salmeterol/fluticasone combination with less favourable estimates for the single components. In the UK, it is commonly considered that treatments falling below $£ 20,000$ per QALY are likely to be considered cost-effective. At a threshold willingness to pay for a QALY of $\$ 50,000$ (conventional value in the USA), the likelihood for the combination treatment, salmeterol and fluticasone being cost-effective is $\sim 0.93,0.01$ and 0.03 , respectively, in the Western European region, suggesting that the combination should be preferred to monotherapies on the grounds of cost-effectiveness [52]. In the OPTIMAL trial, the association of the salmeterol/fluticasone combination with tiotropium improved some health outcomes, including the number of exacerbations requiring hospitalisations versus tiotropium alone, but the incremental cost-effectiveness ratio per QALY (from $\$ 145,000$ to $\$ 243,000$ ) compared with tiotropium alone suggested that monotherapy with tiotropium is the most cost-effective choice [53].

\section{Conclusion}

Recent large studies of pharmacological treatments in COPD have definitely helped to define the best therapeutic strategy, although observed benefits may still be considered as limited in terms of effect size. However, a major input of these studies may be not only the demonstration of treatment effects but also the improvement in the knowledge of how COPD should be studied in therapeutic trials. Distinct clinical phenotypes 
defined by cluster analysis of well-characterised populations $[54,55]$ and identification of predictive markers of disease progression and response to treatment are needed to better assess therapeutic interventions [56,57].

In the majority of patients, treatment should not be restricted to pharmacological intervention: pulmonary rehabilitation is another major component of care.

In very specific categories of patients with severe disease, instrumental treatments can be discussed, either to provide respiratory support or to improve lung mechanics.

\section{LONG-TERM OXYGEN THERAPY AND NONINVASIVE VENTILATION}

Long-term oxygen therapy (LTOT) and noninvasive ventilation (NIV) are routinely prescribed in patients with severe COPD. However, debate continues on important issues concerning their indications and methods. The following sections are based on most of the pertinent data published on these two treatments in the past years. This selection does not claim to be exhaustive but intends to outline the main themes in current clinical research developments.

\section{Long-term oxygen therapy}

A review based on the results from six randomised controlled trials summarised the well-recognised mortality benefits of LTOT in a selected group of COPD patients with severe hypoxia (arterial oxygen tension $\left.\left(\mathrm{Pa}, \mathrm{O}_{2}\right)<55 \mathrm{mmHg}\right)$ [58]. Patients should receive optimal treatment and LTOT should be prescribed for $\geqslant 15-18 \mathrm{~h}$ per day, although some authors consider $24 \mathrm{~h}$ to be more beneficial. LTOT did not appear to improve survival in patients with mild to moderate hypoxia or in those presenting with arterial desaturation only at night [58]. LTOT also reduced the number of hospitalisations, increased effort capacity and improved health-related quality of life.

Recently, a National Heart, Lung and Blood Institute working group evaluated the current state of knowledge regarding LTOT, identified research questions of clinical importance and issued specific recommendations for future trials [59]. The group considered that important unsolved issues may include the possible benefits of LTOT in COPD patients with moderate hypoxia. Most studies in these patients did not evaluate judgment criteria other than survival and, for some, interpretation of results was made difficult by a low treatment compliance rate [59]. Moreover, this group gave high priority to solving the question of treating desaturations during sleep. Other important issues concerned the optimal dosage of oxygen supplementation, LTOT compliance and prescription of LTOT in diseases other than COPD.

\section{Ambulatory oxygen therapy}

Another important, and still unsolved, issue is the possible benefits of LTOT in COPD patients who are normoxic at rest but who desaturate during physical activity. The National Heart, Lung and Blood Institute workshop suggested a comparison of oxygen versus room air in such patients. A recent systematic review of 31 randomised controlled studies in 534 patients receiving oxygen or room air provided evidence that oxygen during exercise improves endurance, maximal exercise capacity and breathlessness in patients with moderate to severe COPD [60]. There seemed to be more inconsistent results in patients with diurnal $\mathrm{Pa}_{1} \mathrm{O}_{2}>60 \mathrm{mmHg}$. However, the clinical relevance of these short-term improvements is still unclear as tests in the laboratory may not reflect the physical activity in daily life. There is a clear need to study patients in their homes and daily environment.

Recently, SANDLAND et al. [61] showed that ambulatory oxygen therapy did not increase domestic activity or time spent outside the home, at least in the short-term. They compared the total domestic physical activity and health-related quality of life measures in 20 COPD patients who were randomised to use cylinder oxygen or cylinder air for 8 weeks. Notably, they included patients who were either hypoxic at rest or desaturated on exercise after completing a 7-week pulmonary rehabilitation programme. There was no significant change in domestic activity measured by an activity monitor attached around the waist from 09:00 h to 21:00 h, and patients did not spend more time outside the home. The patients did not improve their health status as measured by the Chronic Respiratory Questionnaire (CRQ). Interestingly, there was a gradual increase in the number of cylinders used over the 8 weeks in the oxygen group. It is possible that the benefits of ambulatory oxygen in patients need time to become clinically relevant.

Adherence to treatment is an important contributor to effectiveness. In a randomised controlled trial, NONOYAMA et al. [62] showed that patients with COPD and exertional hypoxia used little more than $1 \mathrm{~h}$ of ambulatory oxygen daily, mostly from concentrators. There was no large discrepancy between self-reported (median of $1.3 \mathrm{~h}$ per day) and measured equipment usage (median of $1.2 \mathrm{~h}$ per day). Individual selfreported values seemed to be reasonably accurate when $<2 \mathrm{~h}$ per day but inaccurate for more prolonged use. Patients seemed to prefer concentrator use rather than cylinder use, probably for practical reasons. In another study, NONOYAMA et al. [63] also showed that health-related quality of life was not improved by using ambulatory oxygen therapy in COPD patients with desaturation during room-air 6-min walk tests (6MWT) but no hypoxia $<60 \mathrm{mmHg}$ during the day. The authors did not find any apparent effect of oxygen on any of the domains of the CRQ or the St George's Respiratory Questionnaire (SGRQ). Therefore, it is important to consider that if ambulatory oxygen therapy really improves acute exercise performance in patients with COPD, this improvement does not systematically translate into symptomatic benefits for patients during activities of daily living. QUANTRILL et al. [64] showed that short-burst oxygen therapy may shorten recovery time following activities of daily living in a selected group of patients with COPD, but that the magnitude of effect was small.

\section{The importance of technology}

To obtain good compliance with ambulatory oxygen therapy the gas reservoirs should be the most portable and least cumbersome systems possible. Oxygen conserving devices may also promote portability and autonomy and are now available either on liquid oxygen reservoirs or the most recent portable oxygen concentrators. NASILOWSKI et al. [65] showed that the effectiveness of oxygen supply provided by a portable oxygen concentrator did not differ from a liquid oxygen device when tested during a 6MWT in COPD patients with hypoxia at 
basal state $\left(\mathrm{Pa}_{\mathrm{a}} \mathrm{O}_{2}<60 \mathrm{mmHg}\right)$. Comparison of these devices is easy when using continuous oxygen flows but becomes much more difficult when the portable device is equipped with a demand oxygen valve whose flow characteristics may vary from model to model. Clearly, the correct way to find out if a device is adapted to a patient is to titrate the oxygen conserving device during a $6 \mathrm{MWT}$, and to repeat this test if the device is changed.

The technological improvements also involve fixed sources of oxygen for long-term treatment at home. Concentrators are becoming lighter, less noisy and use less electrical power. HIRCHE et al. [66] evaluated the combined electrolysis and fuelcell technology (Oxy-Gen Lite ${ }^{\circledR}$; Linde Medical Devices $\mathrm{GmbH}$, Aschau, Germany) that de novo generates high-purity oxygen from distilled water and room air. This nonportable device is equipped with a pulsed valve and was proven to improve arterial oxygen saturation measured by pulse oximetry $\left(\mathrm{Sp}_{\mathrm{p}} \mathrm{O}_{2}\right)$ in 32 COPD patients with hypoxia requiring LTOT and oxygen flow $\leqslant 2 \mathrm{~L} \cdot \mathrm{min}^{-1}$. In their experience, the device was safe and resulted in oxygen saturation comparable to standard oxygen therapy, not only during rest but also during mild physical exertion or overnight sleep [66]. Because of its very low-noise level, very low-energy consumption and running costs, such a device probably has a place, at least in developing countries. In fact, its working principle is not really new as similar generators were already available in some hospitals in Eastern Europe in the 1990s.

Another development is better oxygen delivery with $S \mathrm{p}, \mathrm{O}_{2}-$ based flow control. LOBBI et al. [67] implemented a closed-loop control scheme in a computer simulation program, using pulse oximeter feedback to maintain a target $\mathrm{Sp}_{\mathrm{p}} \mathrm{O}_{2}$ of $91 \%$ by automatically changing the oxygen flow-rate to the patient. The simulation seems to produce accurate improvements in arterial oxygen saturation throughout a wide range of disturbance frequencies and the device is currently tested during sleep in COPD patients. However, its benefits during daily physical activities are less obvious.

\section{Outcomes in patients treated with LTOT}

COPD prevalence is progressively increasing in females and studies have suggested a poorer outcome in females than males. EKSTROM et al. [68] extended this research to severe COPD patients requiring LTOT and found higher relative mortality for females compared with males, both overall and related to respiratory disease, cardiovascular disease and cancer. COLETA et al. [69] showed that readily available parameters, such as dyspnoea intensity and hypoxia severity, may be useful in predicting first-year survival rates in advanced COPD patients receiving LTOT. Hypercapnia is also associated with a poor prognosis, but FREMAULT et al. [70], in a small physiological study, showed that inspired fraction of $\mathrm{CO}_{2}$ did not increase markedly during controlled oxygen therapy using either a facial mask $\left(\mathrm{O}_{2} 10 \mathrm{~L} \cdot \mathrm{min}^{-1}\right)$ or nasal prongs $\left(2 \mathrm{~L} \cdot \mathrm{min}^{-1}\right)$. These data were generated on a short-term basis and should probably be tested in larger populations to identify possible subgroups of responders and nonresponders.

In a comparative study, Rizzi et al. [71] suggested that a disease oriented home-care programme may be effective in reducing mortality and hospital admissions in COPD patients requiring
LTOT. The home-care programme consisted of outpatient clinical/functional evaluations every 6 months with domiciliary assessments by a specific team (including a chest physician, a respiratory nurse and a rehabilitation therapist) every $2-3$ months, or more as needed. Another approach is telemonitoring, as recently shown by VITACCA et al. [72] in a randomized study. After deduction of telemonitoring costs, the average costs were $33 \%$ less in 240 patients with chronic respiratory failure treated with LTOT or NIV at home. Patients with COPD seemed to derive greater advantages from nursecentred tele-assistance with fewer hospitalisations, emergency room admissions and urgent GP calls or exacerbations.

\section{Long-term NIV}

The benefits of long-term NIV+LTOT compared with LTOT alone in patients with severe stable COPD are still being debated. Most studies were designed to study gas exchanges rather than the outcomes now considered as essential for COPD treatment trials, such as dyspnoea, health-related quality of life and frequency of exacerbations [73]. A recent systematic review including six randomised controlled and nine nonrandomised controlled trials (crossover design) showed that randomised trials did not find improved gas exchanges with NIV, while crossover trials did [74]. Lung hyperinflation and diaphragmatic work of breathing were reduced but only in nonrandomised studies. Significant reduction of dyspnoea with NIV was consistently reported in the randomised trials, and all three studies that assessed quality of life found a significant improvement with NIV. Mortality was not significantly reduced in the two randomised trials with $a \geqslant 1$ yr follow-up. The authors concluded that long-term NIV+LTOT may have an adjunctive role in the management of chronic respiratory failure in a subset of COPD individuals with maximal medical treatment.

Since this systematic review, a new randomised controlled study that recruited the largest number of patients and followed them for the longest period of time has been published [75]. McEvor et al. [75] compared survival, lung function and quality of life in 72 patients with severe hypercapnic COPD who were randomised to receive NIV+LTOT versus 72 patients randomised to receive LTOT alone. The authors took great care to exclude patients with coexisting sleep apnoea syndrome and to obtain satisfactory nocturnal NIV by titrating the ventilator during polysomnographic recordings. During a mean follow-up of $2.21 \mathrm{yrs}$, NIV+LTOT was associated with an improvement in survival, as attested by the adjusted but not the unadjusted Cox model (adjusted HR 0.63, 95\% CI: 0.40-0.99, p=0.045; unadjusted HR $0.82,95 \%$ CI $0.53-1.25, \mathrm{p}=$ nonsignificant). FEV1 and arterial carbon dioxide tension $\left(\mathrm{Pa}_{1}, \mathrm{CO}_{2}\right)$ measured at 6 and 12 months were not different between groups but NIV was associated with significant improvements in sleep quality and sleeprelated hypercapnia. However, mean NIV compliance was rather low $\left(4.5 \pm 3.2 \mathrm{~h} \cdot\right.$ night $\left.^{-1}\right)$ despite several days spent familiarising the patients with their ventilator. Moreover, inspiratory positive airway pressure values were surprisingly low (12.5-13.4 $\left.\mathrm{cmH}_{2} 0\right)$, corresponding to very low pressure support. This may explain why this study showed a deteriorated quality of life under NIV+LTOT, as attested by several subscales of the Short Form (SF)-36 questionnaire and 
profile of mood states questionnaire. Although this study is the first to demonstrate a survival advantage for long-term NIV in patients with severe COPD, it also suggests that the ventilator settings and NIV compliance are probably important in obtaining health-related benefits from treatment.

\section{Who are NIV responders?}

BUDWEISER et al. [76] evaluated predictors of survival in 188 COPD patients (mean FEV1 $31.0 \pm 9.6 \%$ pred; mean $\mathrm{Pa}_{\mathrm{a}} \mathrm{CO}_{2}$ $56.3 \pm 9.4 \mathrm{mmHg}$ ) treated with home NIV. In their study with $32.2 \pm 24.3$ months follow-up, mortality rates were rather similar to those from currently published cohorts in the literature (1-, 2- and 5-yr mortality rates of $16 \%, 35 \%$ and $74 \%$, respectively). Multivariate analysis identified only age, BMI, residual volume (RV)/total lung capacity (TLC) and base excess as independent predictors of survival $(p<0.05)$. Notably, the degree of metabolic compensation of chronic hypercapnia was a more reliable and consistent predictor than $\mathrm{Pa}, \mathrm{CO}_{2}$. The fact that nutritional status and lung hyperinflation were independent prognostic factors confirms that a multidimensional therapeutic approach is also valuable in severe COPD patients and should be added to assessments currently performed in clinical studies involving long-term NIV [76].

The importance of hyperinflation was also emphasised in a study by NicKOL et al. [77], which suggested that decreased gas trapping and increased ventilatory sensitivity to $\mathrm{CO}_{2}$ may be the principal mechanisms explaining gas-exchange improvements in patients with COPD under long-term NIV. According to physiological data collected in 19 patients 3 months after starting NIV, these two distinct mechanisms seemed to show more clinical relevance than any improvement in respiratory muscle fatigue, or modification in pulmonary mechanics. Indeed, at day 5 after the start of NIV there was an increase in some volitional measures of inspiratory and expiratory muscle strength, but not in isolated diaphragm strength. These preliminary results suggest that the implementation of longterm NIV in COPD patients should focus on appropriate settings to decrease lung hyperinflation, and appropriate nocturnal monitoring to minimise the $\mathrm{Pa}_{1} \mathrm{CO}_{2}$ increments during sleep.

\section{High-intensity NIV for long-term COPD patients}

WINDISCH et al. [78] recently introduced and developed the concept of high-intensity NIV to optimise ventilatory assistance in the specific subgroup of stable hypercapnic COPD patients. This approach aimed to deliver the maximal tolerated inspiratory positive airway pressure to provide a maximal decrease in nocturnal $\mathrm{Pa}, \mathrm{CO}_{2}$. There are two opposing clinical practices when setting a ventilator for chronic respiratory failure. Some chest physicians give preference to spontaneous modes delivering pressures as low as possible to avoid gastric inflation, nontriggered cycles and deterioration in sleep architecture. Other physicians clearly prefer pressure-controlled modes to guarantee delivery of an effective volume. Along the same line they use high inspiratory pressures, usually adjusted for patient comfort and tolerance. Awaiting randomised studies currently in progress, WINDISCH et al. [79] recently reported their experience and outcomes in 73 severe COPD patients receiving highintensity NIV for at least $1 \mathrm{yr}$. Mean inspiratory positive airway pressures were $28 \pm 5 \mathrm{cmH}_{2} \mathrm{O}$ and mean back-up frequency rates were $21 \pm 3 \cdot \mathrm{min}^{-1}$ to approach a controlled ventilatory mode. This method led to significant improvements in alveolar ventilation, lung function and haematocrit after 2 months. Only $16(22 \%)$ patients required hospitalisation due to exacerbation during the first year, with anaemia increasing the risk for exacerbation. 2- and 5-yr survival rates for all patients were $82 \%$ and $58 \%$, respectively. For the authors, such positive results emphasise the need for randomised controlled trials that are currently recruiting, with the aim of evaluating the impact on survival and frequency of exacerbations [79]. Assessment of the potential deleterious effects of this NIV method on sleep quality and patient-ventilator interactions will also be necessary.

\section{NIV and pulmonary rehabilitation}

A recent NIV development in the management of severe stable COPD patients concerns its use during rehabilitation programmes to improve exercise tolerance and health-related quality of life. The first approach involves evaluation of how nocturnal NIV may provide additional benefits to patients starting a pulmonary rehabilitation programme. In a nonrandomised controlled study, KoHNLEIN et al. [80] recruited 40 patients with GOLD stage IV COPD and initiated nocturnal NIV plus a hospital-based pulmonary rehabilitation programme. The outcomes of rehabilitation were compared with those of 40 matched control patients who underwent the same programme. This approach was feasible and accepted by the patients who showed NIV observance for $7.9 \pm 0.5 \mathrm{~h} \cdot$ night $^{-1}$. In these patients nocturnal NIV was associated with significant improvements in the 6MWT and the longest non-stop walk, compared with patients without nocturnal ventilatory support. Health-related quality of life, assessed by the SF-36 questionnaire, improved moderately or greatly in patients receiving NIV in the physical, vitality, social function and mental health categories, while control patients improved moderately in vitality only [80]. Therefore, long-term NIV seemed to enhance the clinical benefits of pulmonary rehabilitation in advanced stage COPD. It should be noted that this study included COPD patients with variable $\mathrm{Pa}_{1} \mathrm{CO}_{2}$ levels at stable state, but the subgroup analysis revealed similar effects in patients with $\mathrm{Pa}, \mathrm{CO}_{2}$ superior or inferior to $45 \mathrm{mmHg}$. A similarly designed but randomised study compared 37 COPD patients treated with nocturnal NIV in addition to pulmonary rehabilitation and 35 COPD patients with pulmonary rehabilitation alone [81]. After 3 months, the authors found that NIV use was associated with significantly improved daytime $\mathrm{Pa}_{\mathrm{a}} \mathrm{CO}_{2}$ and daily step counts, possibly secondary to a significantly increased daytime resting minute ventilation [81]. Moreover, NIV use was associated with a significant improvement in the fatigue domain of the CRQ and a significant improvement in the Maugeri Respiratory Failure questionnaire total score and its cognition domain. The authors included a majority of patients with moderate daytime hypercapnia, but carefully monitored their patients to deliver clinically relevant inspiratory pressures and to obtain satisfactory compliance with the nocturnal treatment [81]. Clearly, these data suggest relevant clinical benefits for pulmonary rehabilitation associated with nocturnal NIV.

The second approach involves the use of NIV during exercise in a rehabilitation programme. DREHER et al. [82] studied the impact of high-intensity $\mathrm{NIV}+\mathrm{O}_{2}$ versus $\mathrm{O}_{2}$ alone during 
6MWTs in 20 patients with severe COPD already treated with nocturnal NIV. Of note, the patients were ventilated with the same settings as those used during the night. The authors found that $\mathrm{Pa}_{1} \mathrm{O}_{2}$, dyspnoea score and walking distances significantly improved when walking with high-intensity NIV [82]. This approach may be of limited impact in clinical management as improvements in dyspnoea and walking distance are probably impaired by the weight of the ventilatory equipment. However, this study demonstrated that NIV may provide additional benefits in the palliative treatment of patients with severe COPD through mechanisms that remain poorly understood. The benefits were due to the ventilation itself and not to the oxygen administered, even when using high oxygen flow rates [83].

\section{What is the impact of long-term NIV on quality of life?}

The meta-analysis by KoloDzIEj et al. [74] clearly showed a positive impact of long-term NIV on health-related quality of life. A recent observational study using the SF-36 questionnaire showed similar results [84]. However, in most studies quality of life is a secondary end-point and its evaluation is, therefore, not powered to provide definite conclusions. Therefore, there is a clear need for large prospective studies on this topic using the right tools. The widely used SF-36 questionnaire is a generic scale, but specific questionnaires dedicated to patients with chronic respiratory failure have been created. In a multicentre study, WINDISCH [85] compared the information provided by the SF-36 to the recently validated Severe Respiratory Insufficiency (SRI) questionnaire in 27 patients with COPD, 29 with restrictive thoracic disorder, 17 with neuromuscular disease, nine with obesity-hypoventilation syndrome and three with chronic respiratory failure of various causes. Data on hospitalisations, side-effects and health-related quality of life were collected 13 months following initiation of home NIV. This study showed that the mean SRI summary scale (range 0-100) improved significantly in all 85 patients. SF-36 scores also improved, but the SRI was superior in detecting health-related quality of life changes. Overall improvements in health-related quality of life secondary to NIV use were similar in COPD patients compared to patients with thoracic disorders or neuromuscular diseases. In contrast, some changes differed significantly between groups in several specific domains. This study confirmed that the SRI questionnaire is a very powerful tool and should be incorporated into future trials and evaluations of long-term NIV.

\section{Conclusion}

Significant knowledge has been acquired in the past years on respiratory assistance in patients with severe COPD. Technical issues concerning oxygen devices and NIV parameters appear to influence clinical benefits and must be incorporated into future assessments. There is clearly a need for cohort studies and long-term prospective assessments based on more relevant and reproducible end-points. Such a new approach may be similar to that used recently for pharmacological treatments in less severe COPD patients, and will hopefully provide similar constructive lessons for clinical management.

\section{SURGERY FOR EMPHYSEMA}

Emphysema causes progressive and irreversible destruction of lung parenchyma [86]. It can lead to incapacitating dyspnoea by destruction of alveoli, decrease in the surface area available for gas exchange, as well as pulmonary hyperinflation altering the mechanical properties of the respiratory system. These modifications in pulmonary mechanical forces and their subsequent effects on the inflammatory cascade are thought to play a key role in disease progression [87]. In recent years, studies have shown that dynamic as well as static hyperinflation can significantly contribute to dyspnoea in subjects with emphysema [87, 88]. Smoking cessation, inhaled bronchodilators and corticosteroids, and home oxygen therapy offer certain benefits in emphysema but a majority of patients remain symptomatic despite optimal medical therapy. Since the beginning of the 20th century, a variety of surgical approaches and techniques have been described to improve function and/or survival in patients with emphysema [89]. Currently, only three procedures may be considered, namely bullectomy, lung volume reduction surgery (LVRS) and lung transplantation [89]. Ideally, each of these procedures would have specific indications, leading to individualised tailoring of surgery. In reality, there is a large degree of overlapping of indications, and several candidates could be suitable for more than one procedure. In fact, there is a continuum of lesions between giant bullae, heterogeneous emphysema and homogeneous emphysema. Similarly, functional improvement following bullectomy and LVRS share some mechanisms. In this section, a brief review of literature concerning bullectomy and LVRS will be provided.

\section{Bullectomy}

A significant fraction of emphysematous patients have pulmonary bulla; in a small proportion of them, bulla are giant and thought to participate in respiratory impairment and dyspnoea, making them possibly accessible to surgical correction $[90,91]$. Giant bulla have been thought to be responsible for compression of adjacent parenchyma, secondary to progressive increase in size of the bulla by a check-valve mechanism, with subsequent loss of function [90, 91]. More recently, it has been pointed out that bullae could not only have a compressive effect but also redirect airflow from surrounding lung to themselves [92]. Following this hypothesis, the sequence of events would be as follows: a bulla would initially originate from local destruction of lung parenchyma and, as volume rises, its compliance would progressively increase in comparison with adjacent less destroyed lung, resulting in a preferential airflow to the bulla (which continues to expand) and a reduced flow to adjacent tissue, which retracts because of preserved elastic recoil [92]. Thus, surgical removal of a giant bulla would result in either removal of compression of adjacent lung tissue (and/or mediastinum or diaphragm) and/or restoration of airflow in uncompressed but hypoventilated parenchyma [90-92].

\section{Patient selection}

The management of patients with asymptomatic giant bulla is controversial: although some authors advocate simple followup, in order to avoid possible operative complications, most suggest resection in the case of bulla occupying more than half of hemithorax and/or being responsible for collapse of adjacent lung, and/or showing progressive enlargement at follow-up [93-95]. 
Patients with symptomatic giant bulla are generally considered as surgical candidates: symptoms include dyspnoea, haemoptysis/pulmonary haemorrhage and chest pain. Pneumothorax complicating a ruptured bulla also represents an indication for surgery, as well as irregularities in wall of bulla suspect of a neoplastic aetiology $[93,96]$. With respect to dyspnoea, the most frequent symptom, it is often difficult to determine if it originates from a bulla or from underlying COPD with possible emphysema distributed elsewhere in the lung [93, 96]. Thus, pre-operatively the predicted benefit of surgery is often questionable and surgical indication controversial, especially in the case of bullae occupying $<50 \%$ of the hemithorax $[93,96]$. However, resection of bullae of $<30 \%$ of the hemithorax and with no associated adjacent lung collapse is generally considered of no functional advantage $[93,96]$.

Thus, the gray zone is represented by bullae of intermediate size (more than one third and $<50 \%$ ). In these cases, careful preoperative anatomical and functional assessment may help in predicting outcome, consequently establishing surgical indication [93, 96]. Thoracic computed tomography (CT) scan quantifies the size of bullae, accurately determines the extent of adjacent collapsed lung parenchyma and assesses pathological changes (especially emphysematous ones) in other parts of lungs [97]. Nowadays, the quality of evaluation of lung vasculature by CT scan is largely sufficient to consider pulmonary angiography as unnecessary. Ventilation-perfusion scan is part of the frequently recommended pre-operative work-up because of its usefulness in assessing the vascular and parenchymal alteration in the remaining lung [98, 99]. Pulmonary functional testing should include determination of residual volume and carbon monoxide transfer factor [93, 96]. Assessment of the communicating/non-communicating character of bulla by the difference of RV between plethysmography and the helium dilution technique is no longer recommended, as outcomes following resection of both communicating and non-communicating giant bullae have been shown to be similar $[100,101]$. Impairment of the diffusing capacity of the lung for carbon monoxide $(\mathrm{DL}, \mathrm{CO})$ is considered a marker of worse longterm outcome after surgery [102]; however, reversible conditions leading to extreme airway obstruction can give falsely depressed results for $D \mathrm{~L}, \mathrm{CO}$.

\section{Surgical technique}

Removal of volume occupied by the bulla with maximum preservation of non-bullous lung parenchyma may be achieved by either resection or elective endocavitary drainage [93]. This last approach, which represents a modification of the Monaldi technique for treatment of tuberculous cavities, was popularised by a team at the Brompton hospital (London, UK) at the end of the 1990s, with the idea that avoiding a large thoracotomy (a 7-cm thoracotomy is necessary for placement of drainage and purse strings, and to perform talc poudrage and pleural drainage) would reduce operative mortality in patients with compromised pulmonary function [103]. However, this approach requires a relatively long hospital stay. In addition, it is not really uninvasive and mortality remains important in patients with very severe respiratory insufficiency. Therefore, surgical resection is now favoured. With respect to the operative approach, thoracotomy, sternotomy (for bilateral disease) or video-assisted thoracoscopy may be employed [93].
Regardless of the approach chosen, anatomic resection (lobectomy) is avoided unless otherwise needed (i.e. for treatment of coexisting lung cancer), with the aim of preserving the maximum of lung function. Post-operative air leak should be prevented by buttressing the suture line by either the everted interior walls of the bulla or employing reinforcement by PTFE or alginate; bovine pericardial strips are no longer employed because of safety concerns [93].

\section{Outcomes}

Results of giant bullectomy in terms of operative morbidity and mortality as well as of short- and long-term functional improvement are heterogeneous because of wide variability among reported series in terms of pre-operative respiratory impairment, surgical technique, quality and duration of follow-up [93, 96]. Operative morbidity includes prolonged air leak, subcutaneous emphysema, cardiac arrhythmia, postoperative infection and respiratory impairment with necessity of mechanical ventilation $[93,96]$. Complications occur in a substantial percentage of operated patients (generally 15-50\%) and figures as high as $79 \%$ have been reported by the St Louis team, whose patient population had a mean pre-operative FEV1 of $34 \%$ pred and necessitated continuous supplemental oxygen in $42 \%$ of cases [104]. Operative mortality is also variables with figures ranging from 0 to $14 \%$ [93]. A metaanalysis published in 1996 on 22 published series found a weighted operative mortality of $8 \%$ [105]. In 2004, SCHIPPER et al. [104] reported a $2.3 \%$ mortality rate. In 2005, PALLA et al. [106] reported no operative deaths in 41 giant bullectomies. All the studies report dyspnoea relief in a percentage of operated patients ranging 75-100\% [93]. VEJLSTED and HALKIER [107] reported $100 \%$ early symptomatic improvement, which persisted at 5 yrs in $81 \%$ of cases and very similar results were reported by OHTA et al. [108]. In the experience of the St Louis team, $86 \%$ of patients reported symptomatic improvement of dyspnoea 6 months after surgery, 10\% had no change and $4 \%$ reported worse dyspnoea. At 3 yrs follow-up, $81 \%$ still had improved dyspnoea, $11 \%$ no change and $8 \%$ had worsening dyspnoea compared with baseline [104]. Objective improvement in lung function tests has also been reported in several studies. Since the report by FitzGERALD et al. [102], who reported an improvement between $50 \%$ and $200 \%$ of preoperative FEV1, other studies have shown values ranging from $25 \%$ to $60 \%$ [93]. In the experience of SCHIPER et al. [104], FEV1 improved from mean baseline value of $34 \%$ pred to $55 \%$ at 6 months then declined to $49 \%$ at 3 yrs, which was still significantly improved in comparison with baseline [104]. In the experience of DEGIACOMO et al. [109], patients with less impaired pre-operative FEV1 had the greatest improvement in their functional tests, but patients with FEV1 $<35 \%$ pred were still functionally and symptomatically improved. Finally, in the experience of PALLA et al. [106] on 41 giant bullectomies, all patients had post-operative FEV1 and dyspnoea improvement but at $5 \mathrm{yr}$ follow-up those with underlying severe emphysema had returned to the pre-operative state, whereas those with more preserved lung parenchyma experienced long-lasting improvement.

\section{Lung volume reduction surgery}

LVRS consists of the resection of emphysematous lung parenchyma, usually at the apices. It aims at improving 
respiratory system mechanics by decreasing pulmonary hyperinflation and reformatting the lung within the thoracic cavity. Several surgical approaches have been described but LVRS is most commonly performed bilaterally via median sternotomy or thoracoscopy using a linear stapling device. The "resizing" principle proposed by BRANTIGAN et al. [110] explains the potential physiological benefit of lung volume resection in emphysema [111]. Hence, LVRS is thought to act by decreasing lung RV and improving the RV/TLC ratio. This is thought to make the previously over distended thoracic cavity more compliant and improve global respiratory mechanics, as reflected by improvements in spirometry (FEV1 and forced vital capacity (FVC)), lung volume and exercise capacity in selected patients, results that were corroborated by the National Emphysema Treatment Trial (NETT).

In 1993, COOPER et al. [111] proposed bilateral LVRS through median sternotomy, with atypical resection of $20-30 \%$ of volume of each lung by linear cutting/stapling devices, and buttressing of mechanical sutures. The procedure ameliorated dyspnoea, increased exercise tolerance and improved quality of life in most of the initial 20 patients who underwent the operation. Concomitant improvement of FEV1, hyperinflation and alveolar gas exchange was also observed and the procedure gained widespread diffusion. Because of concerns about safety, the US government-sponsored healthcare coverage (Medicare) stopped funding the operation in 1996. Subsequently, the National Heart, Lung and Blood Institute promoted a randomised clinical trial comparing LRVS with medical therapy for severe emphysema, known as NETT [112]. The primary outcome parameters were overall mortality and maximal exercise capacity [112, 113]. In this study, 3,777 patients with severe emphysema were evaluated between January 1998 and July 2002 [113]. After completion of a 6-10week programme of pulmonary rehabilitation 1,218 patients (compared with the 2,500 initially planned) in 17 centres were randomly assigned to continued medical treatment $(n=610)$ or bilateral LVRS $(n=608)$. A benefit in terms of mortality was demonstrated in a subgroup of patients with predominant upper lung emphysema and poor exercise capacity [113]. Although several criticisms have been raised on the methodology employed to draw the published conclusions, the NETT trial and subsequent secondary analyses actually represent the most reliable source of data on LVRS and constitute the basis for recommendations in current clinical practice.

\section{Patient selection}

In the initial study by COOPER et al. [111], as well as in their updated study [114], the selection criteria were quite large. Patients could enter the LVRS programme if they had stopped tobacco smoking, were able to participate to a rehabilitation programme, had marked hyperinflation and airflow obstruction as well as a $D \mathrm{~L}, \mathrm{CO}<50 \%$, but an essentially normal cardiovascular function. Exclusion criteria were severely impaired alveolar gas exchanges and extremely low or high BMI. Thus, as acknowledged by the authors, the selection process was subjective in many ways. In the NETT trial [113], patients could be initially randomised in case of high-resolution CT evidence of bilateral emphysema, FEV1 $\leqslant 45 \%$ pred, TLC $\geqslant 100 \%$ pred, RV $\geqslant 150 \%$ pred, oxygen tension $\geqslant 45 \mathrm{mmHg}$, carbon dioxide tension $\leqslant 60 \mathrm{mmHg}$ and post-rehabilitation $6 \mathrm{MWT} \geqslant 140 \mathrm{~m}$.
However, an interim analysis [115] identified a subgroup of 140 $(16 \%)$ patients with an excess 30-day mortality and little chance of improved functional status after surgery: characteristics of these patients were $\mathrm{FEV} 1<20 \%$ pred and either homogeneous emphysema or $D L, C O<20 \%$ pred. On the basis of these data, it is currently recommended that work-up of candidates to LVRS should include exhaustive pre-rehabilitation and post-rehabilitation respiratory and cardiac function assessment, as well as thoracic CT scan and ventilation/perfusion scan $[93,96]$. This last investigation is essential to identify less functional areas of the lung, which will constitute targets for resection $[93,96]$.

\section{Surgical technique}

In the study by COOPER et al. [111], LVRS was performed by median sternotomy. Several other approaches have been described, including unilateral or staged bilateral thoracotomy, and video-assisted thoracic surgery [93]. In the NETT trial, eight centres performed the operation by median sternotomy, three by video-assisted thoracic surgery and six by sternotomy or video-assisted thoracoscopy, all patients were selected randomly [113]. Regardless of the operative approach, lung reduction implies resection of a significant amount of lung parenchyma. COOPER et al. [111] described an inverted Ushaped line of excision from the medial aspect of each upper lobe toward the apex and down to the posterolateral aspect. In a more recent publication [114], they suggested a modification of the technique with subtotal non-anatomical resection of right upper lobe and upper portion of the left upper lobe (thus excluding lingula) with a line of excision beginning at the level of the fissure and progressing straight towards the posterolateral parts of the lobes. In any case, linear stapler devices (and buttressing of suture line) are employed. In the NETT trial, details of surgical technique are not reported; it is stated that wedge resection of $20-35 \%$ volume of each lung was carried out, targeting the most diseased areas [113].

\section{Outcomes}

In the updated study by COOPER et al. [114], 250 consecutive patients treated by LVRS through median sternotomy were retrospectively evaluated. The in-hospital mortality was $4.8 \%$. Re-intubation and mechanical ventilation was required in $7.2 \%$ of patients, whereas the more common complication was prolonged air-leak, which occurred in $45 \%$ of patients. KaplanMeier survival rates after LVRS are shown in table 2, which also shows that FEV1 was significantly and durably improved following surgery. Similarly, a significant reduction of RV occurred. The percentage of patients requiring continuous supplemental oxygen dropped at 1 and 5 yrs while the mean distance at 6MWT increased (table 2). On the basis of these data, the authors concluded that for most patients, functional benefit lasted at least 5 yrs. Of note, $7.2 \%$ of these 250 patients subsequently underwent lung transplantation [114].

In the NETT trial [113], the 90-day mortality was significantly $(p<0.001)$ higher in the LVRS group $(7.5 \%)$ compared with the continued medical therapy group (1.3\%). In the LVRS group, mortality was not affected by the type of surgical approach (sternotomy $8.6 \%$ versus VATS $6.1 \% ; \mathrm{p}=0.33$ ) or by the centre where the surgery was performed. With respect to long-term results, there was no significant difference in overall mortality, despite the higher early mortality in the surgery group. 


\begin{tabular}{|c|c|c|c|c|}
\hline TABLE 2 & \multicolumn{4}{|c|}{$\begin{array}{l}\text { Long-term results of lung volume reduction } \\
\text { surgery in a cohort of } 250 \text { patients }\end{array}$} \\
\hline Outcome & Baseline & $1 \mathrm{yr}$ & $3 \mathrm{yrs}$ & $5 \mathrm{yrs}$ \\
\hline Survival rate \% & NA & 94 & 84 & 68 \\
\hline Mean FEV $1 \%$ prec & 25 & 38 & 34 & 30 \\
\hline $\begin{array}{l}\text { Patients requiring } \\
\text { LTOT \% }\end{array}$ & 61 & 12 & & 23 \\
\hline Mean 6MWD m & $\begin{array}{l}280 m \text { pre-rehabilitation } \\
348 m \text { post-rehabilitation }\end{array}$ & 408 & 387 & 351 \\
\hline
\end{tabular}

FEV1: forced expiratory volume in $1 \mathrm{~s}$; \% pred: \% predicted; LTOT: Iong-term oxygen therapy; 6MWD: 6-min walk distance; NA: not applicable. Data taken from [114].

However, functional results were better in the LVRS group: exercise capacity improved more in the LVRS group than in the medical therapy group (table $3, \mathrm{p}<0.001$ ). Furthermore, patients in the LVRS group were significantly more likely to exhibit an improvement in the 6MWT, as well as in FEV1\% predicted, degree of dyspnoea and health-related quality of life. As stated previously, a group of patients at high-risk of early mortality was identified by an interim analysis [115]. After exclusion of this group of patients from the analysis, both 30-day and 90-day mortality rates remained significantly higher in the LVRS group compared with the non-surgery group $(2.2 \%$ versus $0.2 \%$ and $5.2 \%$ versus $1.5 \%$, respectively). Furthermore, duration of hospitalisation in a standard or nursing facility was significantly longer in the LVRS at 1,2 and 4 months after randomisation. However, there was no reduction in mortality in the LVRS group of non high-risk patients during an average 29 months of follow-up. In secondary analysis, the effects of LVRS on mortality varied markedly among subgroups defined according to the presence or absence of predominantly upper-lobe emphysema and the level of exercise capacity at baseline, thus, four subgroups of patients were identified: 1) upper-lobe predominance of emphysema, low baseline exercise capacity; 2) upper-lobe predominance, high baseline exercise capacity; 3) non upperlobe predominance, low baseline exercise capacity; 4) non upper-lobe predominance, high baseline exercise capacity. A low baseline exercise capacity was defined as a maximal workload $\leqslant 25 \mathrm{~W}$ for females and $40 \mathrm{~W}$ for males. LVRS was associated with a decreased probability of death in group 1 $(p=0.005)$, an increased probability of death in group 4 $(p=0.02)$ and a similar probability of death in groups 2 and 3. From a functional perspective, patients in group 1 treated by
LVRS were more likely to have an improvement in their maximal workload ( $>10 \mathrm{~W}$ increase) as well as in the SGRQ at 24 months. However, patients treated by surgery in group 4 had similar low chance of functional improvement as compared with medically treated patients. Patients treated by surgery in group 3 were more likely than those treated medically to have an improvement in the maximal workload and an eight-point change in health-related quality of life scores at 24 months. Finally, patients in group 2 treated by LVRS had a greater chance of having an eight-point improvement of health-related quality of life scores at 24 months.

Several other secondary analyses have been carried out lately by the NETT investigators. In particular, they have reported that the surgical cohort experienced a $30 \%$ reduction in exacerbation frequency $(p=0.0005)$, although there was no difference in exacerbation rate between the medical and surgical cohorts during the year prior to randomisation $(p=0.58)$ [116]. The positive effect on post-randomisation occurrence of exacerbations was greatest in subjects with the largest post-operative improvement in FEV1 $(p=0.04)$. The authors speculated that the post-operative improvement in lung function was possibly responsible for this observed benefit [116]. A persistently positive effect of LVRS on $\mathrm{Pa}_{1} \mathrm{O}_{2}$ has also been reported [117]: oxygen tension when breathing room air was similar in medical and surgical subjects at baseline, but significantly higher in surgically treated patients up to and after 24 months of surgery (table 3, p<0.001). Furthermore, self-reported oxygen use was greater in medical than in surgical subjects at 6, 12 and 24 months.

From a strict methodological point of view, the NETT yielded substantially negative results. Whether the identification of subgroups of patients more likely to benefit from surgery from both a survival and functional point of view on the basis of secondary analyses can be used as a guide for clinical decision making has been an area of controversy [118, 119]. Although one purpose of the NETT was indeed to identify subgroups of patients more likely to benefit from surgery, cut-off values to define response were not pre-specified, which allows to question the significance of results regarding subgroup analyses [119]. It has also been pointed out that the authors of the NETT pre-listed 16 characteristics of patients to be considered to define groups likely to benefit or not from surgery. Thus, to avoid multiple-comparison problems, conservative adjustment (e.g. using the Bonferroni method) would have been necessary. In that case, the $p$-value acceptable for significance would be $0.05 / 16=0.003$; a value that was not reached in any of the outcome comparisons performed within the four subgroups previously described [119]. Thus, results of the NETT with respect to these four different groups of

TABLE 3 Results of the NETT trial

\begin{tabular}{|c|c|c|c|c|}
\hline Outcome & Baseline & 6 months & 12 months & 24 months \\
\hline$>10 \mathrm{~W}$ increase in exercise capacity $\%$ & NA & 28 versus 4 & 22 versus 5 & 15 versus 3 \\
\hline Mean $\mathrm{Pa}, \mathrm{O}_{2} \mathrm{mmHg}$ & 65 versus 65 & 70 versus 64 & 69 versus 64 & 68 versus 62 \\
\hline
\end{tabular}


patients should ideally be confirmed by specifically designed randomised studies. However, it is unlikely that such studies will ever be performed.

Therefore, despite these strong methodological limitations, results of the NETT trial actually represent the most reliable available data on LVRS and constitute the basis for recommendations in current clinical practice.

\section{ENDOSCOPIC LUNG VOLUME REDUCTION}

Considering the detrimental consequences of emphysema on lung mechanics, symptoms and disease progression on the one hand and the costs, morbidity and (in some subgroups) mortality associated with LRVS on the other, recent research has focused on less invasive (i.e. endoscopic) alternatives to achieve lung volume reduction.

\section{Physiological principles}

Three different systems are currently being studied for endoscopic lung volume reduction. They are based on two distinct concepts: closure of anatomical airways and opening of extra-anatomical passages [120].

\section{Closure of anatomical airways}

This consists of blocking air entry into the affected lobe or segment to induce local atelectasis and achieve lung volume reduction [120, 121]. This is achieved by using a device to occlude the lobar or segmental bronchi, or a biological sealant/ remodelling agent that leads to local scarring fibrosis [120]. Collateral ventilation between pulmonary lobes is the main obstacle to achieving atelectasis and obtaining lung volume reduction, especially with occluding devices. This mechanism is particularly important in emphysema where collateral resistance can be lower than airway resistance [122-124]. The Watanabe spigots, unidirectional endobronchial valves and biological remodelling agents are examples of devices engineered to achieve lung volume reduction in this way [120, 125].

\section{Opening extra-anatomical passages:}

By creating extra-anatomical passages in an emphysematous lobe, it is possible to bypass the airway obstruction that limits the emptying airflow. This concept is based on previous studies that have looked at the possibility of creating passages through the thoracic cage to lung regions with severe emphysema [120, 126]. An airway bypass system developed by Bronchus Incorporated (Mountain View, CA, USA) is currently being studied [127].

\section{Devices currently being studied for the endoscopic treatment of emphysema}

Endobronchial valves

Endobronchial valves are devices designed to block air entry but allow it to flow out of the targeted lung lobe or segment. The aim is to induce local lung collapse via atelectasis of the targeted pulmonary lobe while allowing drainage of secretions from this region to potentially reduce the risk of postobstructive pneumonitis. Two companies have developed and studied endobronchial valve systems for the treatment of emphysema: Emphasys Medical (Redwood City, CA, USA) and Spiration Incorporated (Redmond, WA, USA) [120, 128]. The Zephyr valve system designed by Emphasys Medical consists of a cylindrical self-expendable nitinol stent with a central unidirectional silicone valve that resembles a bird's beak (fig. 1). This system is the most widely studied to date and has been tested in a recent randomised clinical trial which is pending publication [129-136]. The valves are inserted using a special catheter which can be inserted through the operator channel of a flexible bronchoscope ( $2.2 \mathrm{~mm}$ diameter). They are placed in the segmental or lobar bronchi of the lobes targeted for treatment (fig. 2), where they ideally generate lobar atelectasis (fig. 3). For patient comfort, as well as precision and the purpose of duration, the procedure is usually performed under general anaesthetic, although it has been successfully performed under conscious sedation and local anaesthesia [120]. If needed, these valves can be safely removed at any moment after insertion by simply grabbing the metallic strut with biopsy forceps. Another currently studied endobronchial valve system is that of Spiration Incorporated. It resembles a silicone umbrella built over a nitinol structure. Air can flow out around the umbrella but does not penetrate the targeted area on inspiration. The insertion technique is similar to that of the Emphasys valve system [120, 137, 138]. A multicentre randomised trial of this valve system is currently underway and some data concerning these valves can be found in abstracts and in a recent feasibility study [138]. PneumRx (Mountain View, CA, USA) has designed a nitinol endobronchial device that acts by retracting local lung parenchyma. No clinical data is available at this time concerning this device.

\section{Airway bypass system}

Based on the work published by MACKLEM et al. [139] on collateral ventilation, Bronchus Incorporated designed a

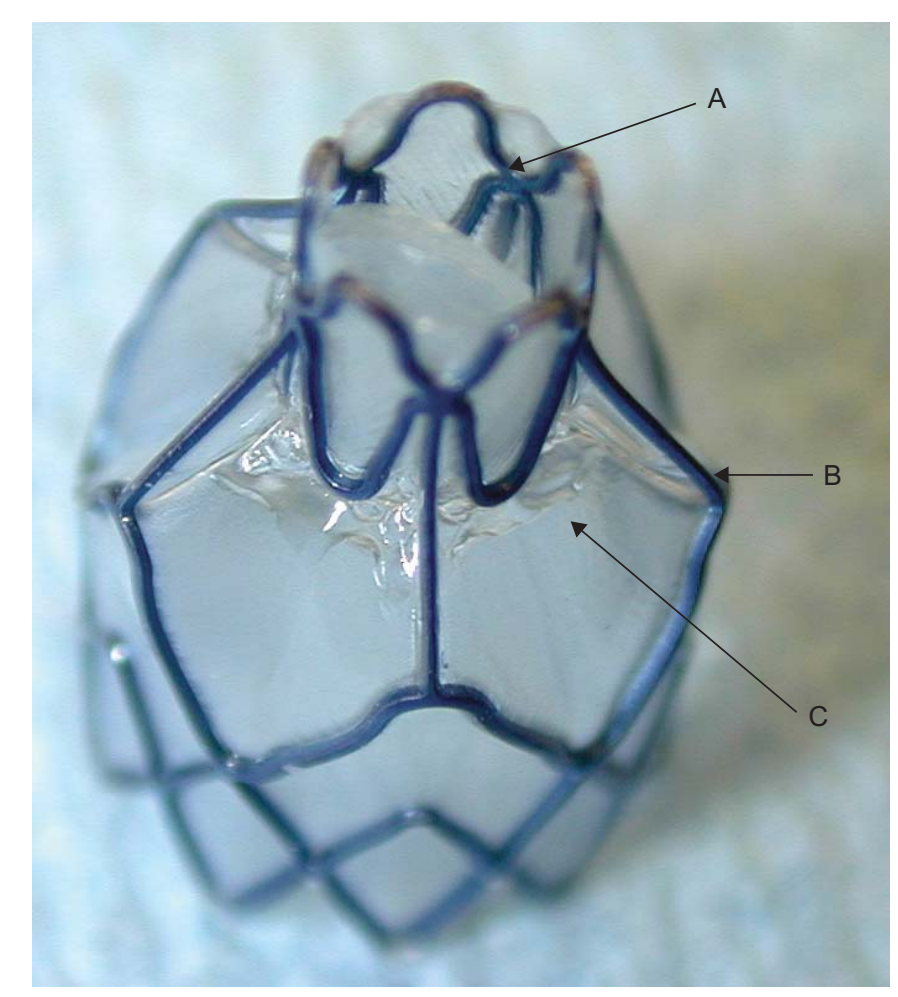

FIGURE 1. The Zephyr valve system (Emphasys Medical, Redwood City, CA, USA). A: bird's beak unilateral valve; B: metallic nitinol structure; C: polyurethane membrane. 
system which aims at bypassing the diseased airways and inducing local deflation by modifying the regional time constants [120, 127, 137, 139]. The procedure consists of three steps. First, an endobronchial Doppler is performed to identify vascular structures around the targeted region. Secondly, the local bronchus is perforated using a dilating catheter similar to those used to dilate coronary artery stenoses and a bypass conduct is created with the adjacent lung parenchyma. Finally, a medicated metallic stent is placed into the new orifice to keep it patent. This procedure has been studied on explanted human emphysematous lungs in which it significantly improved expiratory flow [140, 141]. It has also been tested in 19 emphysema patients who showed immediate but non lasting improvements in dyspnoea and pulmonary function tests (FEV1, FVC and RV). These results are only found in abstract form and no data is available concerning morbidity and mortality related to this device [139]. A randomised double blind multi-centre clinical trial recently finished enrolling 315 patients and results should be available in 2010 .

\section{Biological lung volume reduction}

Biological lung volume reduction using a lung scarring agent and fibrin-based glue has the potential advantage of avoiding the local re-expansion of the targeted lobe or segment caused by collateral ventilation. By acting at the alveolar rather than bronchial level, it also has the possible disadvantage of being irreversible. The actual procedure patented by Aeris Therapeutics (Woburn, MA, USA) consists of a local injection of the two substances via a catheter which is designed to pass through the operating channel of a flexible bronchoscope. It has been the object of animal studies, notably in a sheep emphysema model, where it induced local scarring and atelectasis and improved respiratory mechanics [142]. Subsequently, six subjects with emphysema treated using this process have shown clinical improvement and no major complications [143]. A more recent phase II trial involving 50 emphysema patients has demonstrated significant improvements in FEV1, FVC and RV/TLC at 12 weeks with, again, an acceptable safety record [144]. A multi-centre randomised study has been started in Europe.

\section{Clinical and physiological response in endoscopic therapies for emphysema}

Surgical lung volume reduction has been shown to improve dyspnoea, exercise capacity, FEV1 and FVC, as well as RV in selected emphysema patients. However, available results with endobronchial valves appear to be associated with an inconstant and quite variable clinical response. Different types of response have been observed in subjects who were treated with these devices. Many subjects report improvement in their dyspnoea but show no physiological benefit in exercise capacity or airflow limitation. Thus, it is difficult to distinguish this improvement from a placebo effect. Another group of patients have demonstrated improvements in exercise capacity (6-min walking distance or exercise testing) without measurable changes in pulmonary function at rest. Finally, another group of patients showed a subjective and objective response at rest and during exercise with measurable significant improvements in FEV1 and FVC combined with reductions in $R V$ and $R V / T L C$ ratio.
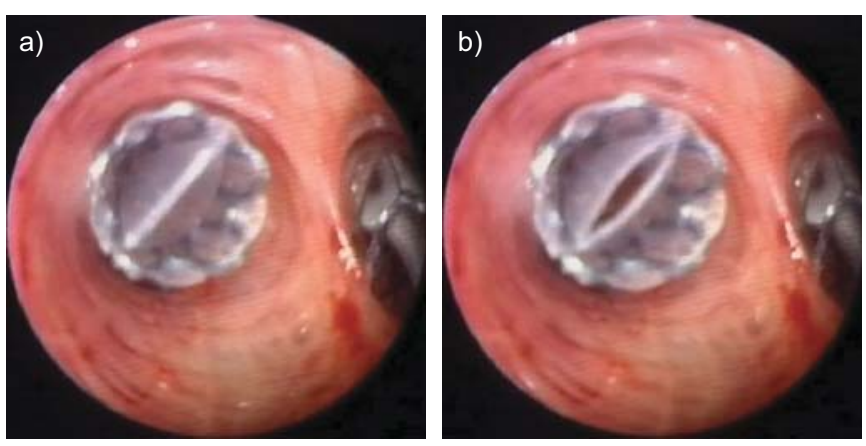

FIGURE 2. The Zephyr valve in vivo. The valve was implanted at the orifice of a sub-segmental bronchus. The images show a closed valve on inspiration (a) which opens on expiration (b).
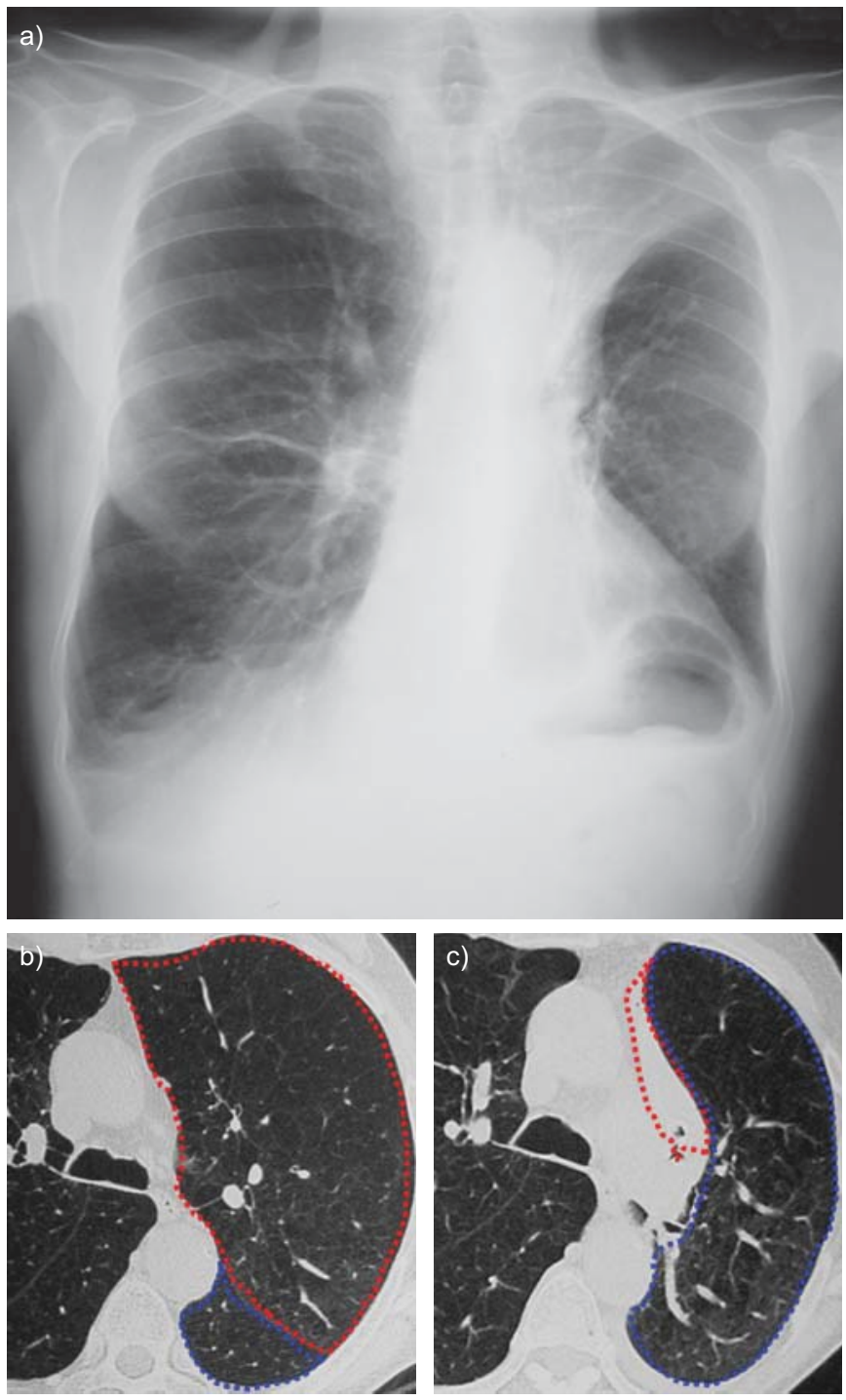

FIGURE 3. Left upper lobe complete atelectasis 2 days after implantation of four endobronchial valves into the left upper lobe in a patient with emphysema a) Chest radiograph after implantation of the valve. Computed tomography scan b) before and c) after implantation. The left upper lobe is circled in red and the lower lobe in blue. 
Early investigations in the initial eight subjects treated with the Emphasys valve have shown a $34 \%$ increase in FEV1 and an $11 \%$ decrease in $\mathrm{RV}$, which reached statistical significance. Radiological lobar collapse was seen in the three patients who had the most important airflow limitation response, whereas it was not seen in the patients with less significant improvement [131]. Subsequent cohorts also demonstrated a wide variability in both symptomatic and physiological response in patients treated with this valve system [129-134]. Results from the first 98 patients who received the Emphasys valve system demonstrated a small but significant increase in FEV1 (10.7 $\pm 26.2 \%$; $\mathrm{p}=0.007)$ and FVC $(9.0 \pm 23.9 \% ; \mathrm{p}=0.024)$, as well as the 6 -min walk distance $(23.0 \pm 55.3 \% ; \mathrm{p}=0.001)$ [132]. Again, the observed symptomatic improvement did not appear to correlate with the degree of improvement of these physiological parameters. In 57 subjects treated with the Spiration valve, CT measurements of atelectasis and volume reduction before and after treatment were correlated with symptomatic response. However, this was not correlated with improvements in pulmonary function tests [145].

HOPKINSON et al. [123] also observed a significant increase in exercise capacity in 19 patients who had received unilateral endobronchial valves. In their cohort, only five subjects had radiological evidence of atelectasis after treatment. This observation was explained by a decrease in dynamic hyperinflation, which was seen even in patients without lobar collapse. Thus, they hypothesised that, although collateral ventilation prevented local collapse, if collateral resistance was high enough this could still result in a decrease in dynamic hyperinflation [124].

In light of these encouraging preliminary results, the Emphasys valve system was the object of a multi-centre randomised clinical trial, the VENT study [146]. In this study, which recruited 312 patients with severe heterogeneous emphysema, standard medical therapy was compared to unilateral endobronchial valve implantation with a 2:1 randomisation ratio in favour of the valves. The primary outcome was improvement in FEV1 and $6 \mathrm{MWT}$ and the study also aimed at establishing the safety profile of this therapy. A pre-treatment computer tomography targeting score was used to determine the lobe(s) that would be occluded with the valves. Patients who received endobronchial valves had a small but significant increase in FEV1 of $6.8 \%(p=0.002)$ and $6 \mathrm{MWT}$ of $5.8 \%(\mathrm{p}=0.02)$. This response was more important in those subjects who had an elevated emphysema heterogeneity score on their pre-treatment CT (difference in severity of emphysema between the different lobes). Over one third of patients with heterogeneous emphysema had a $>15 \%$ increase in FEV1 post-treatment as opposed to only $12.5 \%$ of controls. Presence of a complete fissure in the targeted lobe was another predictor of functional and physiological response, suggesting again that collateral ventilation plays a major role [146].

Overall, endobronchial valves appear safe to use with a mortality rate $<1 \%$ and reported complication rates of $3-$ $17 \%$. Pneumothorax with or without persistent leak, COPD exacerbations, post-treatment respiratory insufficiency and post-obstructive pneumonia were the most commonly reported side-effects $[129,132,134,138,146]$. In the VENT study, the most commonly reported complication was lateoccurring pneumonia in nine $(4.2 \%)$ patients. None of these proved fatal but three patients had to have their valves removed [146]. It has been suggested that pneumothorax after insertion is caused by local collapse rather than iatrogenic trauma since it is more commonly seen in patients with a notable radiological response [132].

The VENT study showed a modest benefit, albeit significant when considering the whole study population [146]. The improvements in FEV1 and 6MWT did not follow a classical bell-shaped distribution but rather showed clear groups of responder and nonresponders. In addition, as opposed to LVRS, endoscopic therapy of emphysema did not have any effect on patient mortality in any subgroup when compared with controls. These arguments were taken into consideration in the recent decision of the US Food and Drug Administration who asked Emphasys to perform an additional trial to validate the predictors of response to their endobronchial valve before allowing its commercial use. After this decision, the company decided not to go forward with this study and ceased production of the Zephyr valve. However, it was recently taken over and a study should be undertaken to predict treatment response. This should be performed by measuring collateral ventilation in situ (during flexible bronchoscopy) with a special catheter. This technique was validated on 11 patients with emphysema in a recent publication and this technique should be made available in the near future [147].

\section{Conclusion}

Outside of smoking cessation and oxygen therapy in hypoxaemic patients, LVRS is the only therapy shown to improve survival in some patients with emphysema. Patients with predominantly apical emphysema, FEV1 and DL,CO $>20 \%$, a poor exercise tolerance and who are deemed fit enough to undergo surgery should be referred to a thoracic surgeon for possible LVRS. Development of less invasive therapies in emphysema could eventually change current practices.

Overall, response to therapy using endobronchial valves has been inconstant and less important than expected. Collateral ventilation probably has a major influence on the physiological and radiological response to endobronchial valve implantation. Even when attempts are made to correctly target therapy, a significant proportion of patients will not show long-term radiological collapse after therapy [135, 136, 148]. Studies are ongoing to evaluate the therapeutic potential of endobronchial valves and the airway bypass systems, as well as biological lung volume reduction. Results of these trials, especially those made with the last two processes since their mode of action differ, should provide additional insight into the problems surrounding collateral ventilation. Their results will greatly influence the future role of endoscopy in the treatment of emphysema. For now, these therapies are experimental and should only be offered to patients who are not candidates for LVRS and as part of clinical trials. Who knows if, in the near future, the therapeutic arsenal in emphysema and COPD will become wider and whether endoscopy will play a role in it.

\section{CONCLUSION}

During the last decades, the treatments available for COPD patients have evolved considerably. They include new aids towards smoking cessation and new long-acting bronchodilators, either alone or in combination with inhaled corticosteroids. New anti-inflammatory agents are also about to be 
made available and other possible candidates are being studied. Although none of these approaches provides a cure, they help to decrease symptoms, increase exercise tolerance, reduce exacerbations and overall improve health-related quality of life. Some may even have modest effects on disease progression. Except maybe in the milder patients, pharmacological treatments have to be associated with other measures including pulmonary rehabilitation, which has also been the topic of a great amount of published evidence.

In the most severe patients, some "instrumental" measures can be discussed. They include respiratory assistance (LTOT and domiciliary NIV) in case of severe hypoxaemic and/or hypercapnic respiratory failure, and restoration of more appropriate lung mechanics through surgery or endoscopic techniques. Obviously, such interventions are or will be restricted to a small minority of carefully selected patients.

For all treatments, it is of utmost importance to define patientcentred objectives in order to select the appropriate corresponding outcome measures and to develop markers predicting response. Measures of daily physical activity may be of interest in this regard $[149,150]$.

Finally, evolutions in treatments make it necessary that guidelines be regularly updated, such as the recent update of the international GOLD guidelines [1]. However, dissemination of these updates is not sufficient to ensure adherence of physicians to guidelines, as shown in several practice surveys or audits on both stable and exacerbated patients. Other measures are necessary, including continuous medical education, reminders, financial incentives, peer review, changes in organisation of care...

\section{STATEMENT OF INTEREST}

A. Cuvelier has received fees for speaking and organising education from Boehringer Ingelheim, GlaxoSmithKline and LFB-Biomédicaments. N. Roche has received fees for speaking, organising education and consulting from Altana Pharma (Nycomed), AstraZeneca, Boehringer Ingelheim, Chiesi, GlaxoSmithKline, MEDA, Mundipharma, Novartis and Pfizer. L-J. Couderc has received fees for organising education from Boehringer Ingelheim and Pfizer, and travel to the ERS Congress was funded by Novartis. P. Devillier has received fees for speaking, organising education and consulting from Altana Pharma (Nycomed), Almirall, AstraZeneca, Boehringer Ingelheim, Chiesi, GlaxoSmithKline, Stallergenes, Pfizer, Schering-Plough, and Merck Sharp and Dohme.

\section{REFERENCES}

1 Rabe KF, Hurd S, Anzueto A, et al. Global strategy for the diagnosis, management, and prevention of chronic obstructive pulmonary disease: GOLD executive summary. Am J Respir Crit Care Med 2007; 176: 532-555.

2 Herland K, Akselsen JP, Skjonsberg OH, et al. How representative are clinical study patients with asthma or COPD for a larger "real life" population of patients with obstructive lung disease? Respir Med 2005; 99: 11-19.

3 Beasley R, Weatherall M, Travers J, et al. Time to define the disorders of the syndrome of COPD. Lancet 2009; 374: 670-672.

4 Puhan MA, Schüneman HJ. How to increase the value of randomised trials in COPD research. Eur Respir J 2009; 34: 552-558.

5 Halpin DMG, Tashkin DP. Defining disease modification in chronic obstructive Pulmonary disease. COPD 2009; 6: 211-225.
6 Dusser D, Bravo ML, Iacono P. The effect of tiotropium on exacerbations and airflow in patients with COPD. Eur Respir J 2006; 27: 547-555.

7 Calverley PMA, Anderson JA, Celli B, et al. Salmeterol and fluticasone propionate and survival in chronic obstructive pulmonary disease. N Engl J Med 2007; 356: 775-789.

8 Celli BR, Thomas NE, Anderson JA, et al. Effect of pharmacotherapy on rate of decline of lung function in chronic obstructive pulmonary disease: results from the TORCH study. Am J Respir Crit Care Med 2008; 178: 332-338.

9 Tashkin DP, Celli B, Senn S, et al. A 4-year trial of tiotropium in chronic obstructive pulmonary disease. N Engl J Med 2008; 359: 1543-1554.

10 Decramer M, Celli B, Kesten S, et al. Effect of tiotropium on outcomes in patients with moderate chronic obstructive pulmonary disease (UPLIFT): a prespecified subgroup analysis of a randomised controlled clinical trial. Lancet 2009; 374: 1171-1178.

11 Miravitlles $M$, Anzueto A. Insights into interventions in managing COPD patients: lessons from the TORCH and UPLIFT studies. Int J COPD 2009; 4: 185-201.

12 Keene ON, Vestbo J, Anderson JA, et al. Methods for therapeutic trials in COPD: lessons from the TORCH trial. Eur Respir J 2009; 34: 1018-1023.

13 Beeh KM, Hederer B, Glaab T, et al. Study design considerations in a large COPD trial comparing effects of tiotropium with salmeterol on exacerbations. Int J COPD 2009; 4: 119-125.

14 Anzueto A, Tashkin D, Menjorge S, et al. One-year analysis of longitudinal changes in spirometry in patients with COPD receiving tiotropium. Pulm Pharmacol Ther 2005; 18: 75-81.

15 Celli B, Decramer M, Kesten S, et al. Mortality in the 4-year trial of tiotropium (UPLIFT) in patients with chronic obstructive pulmonary disease. Am J Respir Crit Care Med 2009; 180: 948-955.

16 O'Donnell DE, Voduc N, Fitzpatrick M, et al. Effect of salmeterol on the ventilatory response to exercise in chronic obstructive pulmonary disease. Eur Respir J 2004; 24: 86-94.

17 O'Donnell DE, Fluge T, Gerken F, et al. Effects of tiotropium on lung hyperinflation, dyspnoea and exercise tolerance in COPD. Eur Respir J 2004; 23: 832-840.

18 Postma DS, Calverley P. Inhaled corticosteroids in COPD: a case in favour. Eur Respir J 2009; 34: 10-12.

19 Suissa S, Barnes PJ. Inhaled corticosteroids in COPD: the case against. Eur Respir J 2009; 34: 13-16.

20 Jones PW, Willits LR, Burge PS, et al. Disease severity and the effect of fluticasone propionate on chronic obstructive pulmonary disease exacerbations. Eur Respir J 2003; 21: 68-73.

21 Puhan MA, Bachmann L, Kleijnen J, et al. Inhaled drugs to reduce exacerbations in patients with chronic obstructive pulmonary disease: a network analysis. BMC Medicine 2009; 7: 2.

22 Wedzicha JA, Calverlet PM, Seemungal TA, et al. The prevention of chronic obstructive pulmonary disease exacerbations by salmeterol/fluticasone propionate or tiotropium bromide. Am J Respir Crit Care Med 2008; 177: 19-26.

23 Rodrigo J, Castro-Rodriguez JA, Plaza V. Safety and efficacy of combined long-acting $\beta_{2}$-agonists and inhaled corticosteroids vs long-acting $\beta_{2}$-agonists monotherapy for stable COPD. Chest 2009; 136: 1029-1038.

24 O'Donnell DE, Sciurba F, Celli B, et al. Effect of fluticasone propionate/salmeterol on lung hyperinflation and exercise endurance in COPD. Chest 2006; 130: 647-656.

25 Nava S, Compagnoni ML. Controlled short-term trial of fluticasone propionate in ventilator-dependent patients with COPD. Chest 2000; 118: 990-999.

26 John M, Bosse S, Oltmanns U, et al. Effects of inhaled HFA beclomethasone on pulmonary function and symptoms in patients with chronic obstructive pulmonary disease. Respir Med 2005; 99: 1418-1424. 
27 Crim C, Calverley PMA, Anderson JA, et al. Pneumonia risk in COPD patients receiving inhaled corticosteroids alone or in combination: TORCH study results. Eur Respir J 2009; 34: 641-647.

28 Sin DD, Tashkin D, Zhang $X$, et al. Budesonide and the risk of pneumonia: a meta-analysis of individual patient data. Lancet 2009; 374: 712-719.

29 Drummond MB, Dasenbrook EC, Pitz MW, et al. Inhaled corticosteroids in patients with stable chronic obstructive pulmonary disease. JAMA 2008; 300: 2407-2416.

30 Singh D, Brooks J, Hagan G, et al. Superiority of "triple" therapy with salmeterol/fluticasone propionate and tiotropium bromide versus individual component in moderate to severe COPD. Thorax 2008; 63: 592-598.

31 Aaron SD, Vandemheen KL, Fergusson D, et al. Tiotropium in combination with placebo, salmeterol,or fluticasone-salmeterol for treatment of chronic obstructive pulmonary disease: a randomized trial. Ann Intern Med 2007; 146: 545-555.

32 Welte $\mathrm{T}$, Miravitlles $\mathrm{M}$, Hernandez $\mathrm{P}$, et al. Efficacy and tolerability of budesonide/formoterol added to tiotropium in patients with chronic obstructive pulmonary disease. Am J Respir Crit Care Med 2009; 180: 741-750.

33 Zuwallack RL, Mahler DA, Reilly D, et al. Salmeterol plus theophylline combination therapy in the treatment of COPD. Chest 2001; 119: 1661-1670.

34 Cosio BG, Soriano JB. Theophylline again? Reasons for believing. Eur Respir J 2009; 34: 5-6.

35 Cosio BG, Iglesias A, Rios A, et al. Low-dose theophylline enhances the anti-inflammatory effects of steroids during exacerbations of COPD. Thorax 2009; 64: 424-429.

36 Calverley PMA, Rabe KF, Goehring UM, et al. Roflumilast in symptomatic chronic obstructive pulmonary disease: two randomised clinical trials. Lancet 2009; 374: 685-694.

37 Fabbri M, Calverley PMA, Izquierdo-Alonso JL, et al. Roflumilast in moderate-to-severe chronic obstructive pulmonary disease treated with long acting bronchodilators: two randomised clinical trials. Lancet 2009; 374: 695-703.

38 O'Byrne PM, Gauvreau G. Phosphodiesterase inhibition in COPD. Lancet 2009; 374: 665-667.

39 Seemungal TAR, Wedzicha JA. Integrated care: a new model for COPD management? Eur Respir J 2006; 28: 4-6.

40 Restrepo RD, Alvarez MT, Wittnebel LD, et al. Medication adherence issues in patients treated for COPD. Int J Chron Obstruct Pulmon Dis 2008; 3: 371-384.

41 Polkey MI, Rabe KF. Chicken or egg: physical activity in COPD revisited. Eur Respir J 2009; 33: 227-229.

42 Garcia-Aymerich J, Lange P, Serra I, et al. Time-dependent confounding in the study of the effects of regular physical activity in chronic obstructive pulmonary disease: an application of the marginal structural model. Ann Epidemiol 2008; 18: 775-783.

43 Garcia-Aymerich J, Serra I, Gomez FP, et al. Physical activity and clinical and functional status in COPD. Chest 2009; 136: 62-70.

44 Garcia-Aymerich J, Hernandez C, Alonso A, et al. Effects of an integrated care intervention on risk factors of COPD readmission. Respir Med 2007; 101: 1462-1469.

45 Vestbo J, Anderson JA, Calverley PMA, et al. Adherence to inhaled therapy, mortality and hospital admission in COPD. Thorax 2009; 64: 939-943.

46 Cazzola M, Matera MG. Emerging inhaled bronchodilators: an update. Eur Respir J 2009; 34: 757-769.

47 McKinstry B, Pinnock H, Sheikh A. Telemedicine for management of patients with COPD. Lancet 2009; 374: 672-673.

48 Yasothan U, Kar S. Therapies for COPD. Nat Rev Drug Dis 2008, 7: 285-286.

49 Cazzola M, MacNee W, Martinez FJ, et al. Outcomes for COPD pharmacological trials: from lung function to biomarkers. Eur Respir J 2008; 31: 416-469.
50 European Medicines Agency. Committee for medicinal products for human use (CHMP). Concept paper on the need for revision of the points to consider on clinical investigation of medicinal products in the chronic treatments of patients with COPD. EMEA/CHMP/EWP/8197/2009. www.ema.europa.eu/pdfs/ human/ewp/819709en.pdf

51 Miravitlles M, Brosa M, Velasco M, et al. An economic analysis of pharmacological treatment of COPD in Spain. Respir Med 2009; 103: 714-721.

52 Briggs AH, Glick HA, Lozano-Ortega G, et al. Is treatment with ICS and LABA cost-effective for COPD? Multionational economic analysis of the TORCH study. Eur Respir J 2010; 35: 532-539.

53 Najafdeh M, Marra CA, Sadatsafavi M, et al. Cost effectiveness of therapy with combinations of long acting bronchodilators and inhaled steroids for treatment of COPD. Thorax 2008; 63: 962-967.

54 Weatherall M, Travers J, Shirtcliffe $\mathrm{P}$, et al. Distinct clinical phenotypes of airways disease defined by cluster analysis. Eur Respir J 2009; 34: 812-818.

55 Burgel PR, Nesme-Meyer P, Chanez $\mathrm{P}$, et al. Initiatives BPCO Scientific Committee. Cough and sputum production are associated with frequent exacerbations and hospitalizations in COPD subjects. Chest 2009; 135: 975-982.

56 Vestbo J, Anderson W, Coxson $\mathrm{HO}$, et al. Evaluation of COPD longitudinally to identify predictive surrogate end-points (ECLIPSE). Eur Respir J 2008; 31: 869-873.

57 Puhan MA, Garcia-Aymerich J, Frey M, et al. Expansion of the prognostic assessment of patients with chronic obstructuve pulmonary disease: the updated BODE index and the ADO index. Lancet 2009; 374: 704-711.

58 Cranston JM, Crockett AJ, Moss JR, et al. Domiciliary oxygen for chronic obstructive pulmonary disease. Cochrane Database Syst Rev 2005; 4: CD001744.

59 Croxton TL, Bailey WC. Long-term oxygen treatment in chronic obstructive pulmonary disease: recommendations for future research. An NHLBI Workshop Report. Am J Respir Crit Care Med 2006; 174: 373-378.

60 Bradley JM, Lasserson T, Elborn S, et al. A systematic review of randomized controlled trials examining the short-term benefit of ambulatory oxygen in COPD. Chest 2007; 131: 278-285.

61 Sandland CJ, Morgan MD, Singh SJ. Patterns of domestic activity and ambulatory oxygen usage in COPD. Chest 2008; 134: 753-760.

62 Nonoyama ML, Brooks D, Guyatt GH, et al. Ambulatory gas usage in patients with chronic obstructive pulmonary disease and exertional hypoxemia. J Cardiopulm Rehabil Prev 2008; 28: 323-329.

63 Nonoyama ML, Brooks D, Guyatt GH, et al. Effect of oxygen on health quality of life in patients with chronic obstructive pulmonary disease with transient exertional hypoxemia. Am J Respir Crit Care Med 2007; 176: 343-349.

64 Quantrill SJ, White R, Crawford A, et al. Short burst oxygen therapy after activities of daily living in the home in chronic obstructive pulmonary disease. Thorax 2007; 62: 702-705.

65 Nasilowski J, Przybylowski T, Zielinski J, et al. Comparing supplementary oxygen benefits from a portable oxygen concentrator and a liquid oxygen portable device during a walk test in COPD patients on long-term oxygen therapy. Respir Med 2008; 102: 1021-1025.

66 Hirche TO, Born T, Jungblut S, et al. Oxygen generation by combined electrolysis and fuel-cell technology: clinical use in COPD patients requiring long time oxygen therapy. Eur J Med Res 2008; 13: 451-458.

67 Lobbi MG, Simonds AK, Dickinson RJ. Oximetry feedback flow control simulation for oxygen therapy. J Clin Monit Comput 2007; 21: $115-123$

68 Ekstrom M, Franklin KA, Strom KE. Increased relative mortality in women with severe oxygen-dependent chronic obstructive pulmonary disease. Chest 2010; 137: 31-36. 
69 Coleta KD, Silveira LV, Lima DF, et al. Predictors of first-year survival in patients with advanced COPD treated using longterm oxygen therapy. Respir Med 2008; 102: 512-518.

70 Fremault A, Silva M, Beaucage F, et al. Inspired fraction of carbon dioxide in oxygen supply to chronic pulmonary disease. Respir Med 2008; 102: 1827-1829.

71 Rizzi M, Grassi M, Pecis M, et al. A specific home care program improves the survival of patients with chronic obstructive pulmonary disease receiving long term oxygen therapy. Arch Phys Med Rehabil 2009; 90: 395-401.

72 Vitacca M, Bianchi L, Guerra A, et al. Tele-assistance in chronic respiratory failure patients: a randomised clinical trial. Eur Respir J 2009; 33: 411-418.

73 Cazzola M, MacNee W, Martinez FJ, et al. Outcomes for COPD pharmacological trials: from lung function to biomarkers. Eur Respir J 2008; 31: 416-469.

74 Kolodziej MA, Jensen L, Rowe B, et al. Systematic review of noninvasive positive pressure ventilation in severe stable COPD. Eur Respir J 2007; 30: 293-306.

75 McEvoy RD, Pierce RJ, Hillman D, et al. Nocturnal non-invasive nasal ventilation in stable hypercapnic COPD: a randomised controlled trial. Thorax 2009; 64: 561-566.

76 Budweiser S, Jorres RA, Riedl T, et al. Predictors of survival in COPD patients with chronic hypercapnic respiratory failure receiving noninvasive home ventilation. Chest 2007; 131: 1650-1658.

77 Nickol AH, Hart N, Hopkinson NS, et al. Mechanisms of improvement of respiratory failure in patients with COPD treated with NIV. Int J Chron Obstruct Pulmon Dis 2008; 3: 453-462.

78 Windisch W, Kostić S, Dreher M, et al. Outcome of patients with stable COPD receiving controlled noninvasive positive pressure ventilation aimed at a maximal reduction of $\mathrm{Pa}\left(\mathrm{CO}_{2}\right)$. Chest 2005; 128: 657-662.

79 Windisch W, Haenel M, Storre JH, et al. High-intensity noninvasive positive pressure ventilation for stable hypercapnic COPD. Int J Med Sci 2009; 6: 72-76.

80 Kohnlein T, Schonheit-Kenn U, Winterkamp S, et al. Noninvasive ventilation in pulmonary rehabilitation of COPD patients. Respir Med 2009; 103: 1329-1336.

81 Duiverman ML, Wempe JB, Bladder G, et al. Nocturnal noninvasive ventilation in addition to rehabilitation in hypercapnic patients with COPD. Thorax 2008; 63: 1052-1057.

82 Dreher $\mathrm{M}$, Storre JH, Windisch $\mathrm{W}$. Noninvasive ventilation during walking in patients with severe COPD: a randomised cross-over trial. Eur Respir J 2007; 29: 930-936.

83 Dreher M, Doncheva E, Schwoerer A, et al. preserving oxygenation during walking in severe chronic obstructive pulmonary disease: noninvasive ventilation versus oxygen therapy. Respiration 2009; 78: 154-160.

84 Tsolaki V, Pastaka C, Karetsi E, et al. One-year non-invasive ventilation in chronic hypercapnic COPD: effect on quality of life. Respir Med 2008; 102: 904-911.

85 Windisch W. Impact of home mechanical ventilation on healthrelated quality of life. Eur Respir J 2008; 32: 1328-1336.

86 The definition of emphysema. Report of a National Heart Lung and Blood Institute, Division of Lung Diseases workshop. Am Rev Respir Dis 1985; 132: 182-185.

87 Suki B, Lutchen KR, Ingenito EP. On the progressive nature of emphysema: roles of proteases, inflammation, and mechanical forces. Am J Respir Crit Care Med 2003; 168: 516-521.

88 Celli BR. Update on the management of COPD. Chest 2008; 133: 1451-1462.

89 Deslauriers J. History of surgery for emphysema. Semin Thorac Cardiovasc Surg 1996; 8: 43-51.

90 Connolly JE, Wilson A. The current status of surgery for bullous emphysema. J Thorac Cardiovasc Surg 1989; 97: 351-361.
91 Greenberg JA, Singhal S, Kaiser LR. Giant bullous lung disease: evaluation, selection, techniques, and outcomes. Chest Surg Clin N Am 2003; 13: 631-649.

92 Mehran RJ, Deslauriers J. Indications for surgery and patient work-up for bullectomy. Chest Surg Clin N Am 1995; 5: 717-734

93 Schipper PH, Meyers BF. Surgery for bullous disease. In Patterson GA, Cooper JD, Deslauriers J, et al., eds. Pearson's Thoracic and Esophageal Surgery. 3rd Edn. Philadelphia, Churchill Livingstone, 2008: pp. 631-652.

94 Gunstensen J, McCormack RJM. The surgical management of bullous emphysema. J Thorac Cardiovasc Surg 1973; 65: 920-925.

95 Lopez-Majano V, Kieffer RF Jr, Marine DN, et al. Pulmonary resection in bullous disease. Am Rev Respir Dis 1969; 99: 554-564.

96 Benditt JO. Surgical options for patients with COPD: sorting out the choices. Respir Care 2006; 51: 173-182.

97 Morgan MD, Denison DM, Strickland B. Value of computed tomography for selecting patients with bullous lung disease for surgery. Thorax 1986; 41: 855-862.

98 Klein RC, Kazemi H, Strieder DJ. Regional lung function in obstructive and bullous emphysema. South Med J 1972; 65: 721-726.

99 Nakahara K, Nakaoka K, Ohno K, et al. Functional indications for bullectomy of giant bulla. Ann Thorac Surg 1983; 35: 480-487.

100 Vishnevsky AA, Nickoladze GD. One-stage operation for bilateral bullous lung disease. J Thorac Cardiovasc Surg 1990; 99 : 30-34.

101 Laros CD, Gelissen HJ, Bergstein PG, et al. Bullectomy for giant bullae in emphysema. J Thorac Cardiovasc Surg 1986; 91: 63-70.

102 FitzGerald MX, Keelan PJ, Cugell DW, et al. Long-term results of surgery for bullous emphysema. J Thorac Cardiovasc Surg 1974; 68: 566-587.

103 Shah SS, Goldstraw P. Surgical treatment of bullous emphysema: experience with the Brompton technique. Ann Thorac Surg 1994; 58: 1452-1456.

104 Schipper PH, Meyers BF, Battafarano RJ, et al. Outcomes after resection of giant emphysematous bullae. Ann Thorac Surg. 2004; 78: 976-982.

105 Snider GL. Reduction pneumoplasty for giant bullous emphysema. Implications for surgical treatment of nonbullous emphysema. Chest 1996; 109: 540-548.

106 Palla A, Desideri M, Rossi G, et al. Elective surgery for giant bullous emphysema: a 5-year clinical and functional follow-up. Chest. 2005; 128: 2043-2050.

107 Vejlsted H, Halkier E. Surgical improvement of patients with pulmonary insufficiency due to localized bullous emphysema or giant cysts. Thorac Cardiovasc Surg. 1985; 33: 335-336.

108 Ohta M, Nakahara K, Yasumitsu T, et al. Prediction of postoperative performance status in patients with giant bulla. Chest 1992; 101: 668-673.

109 De Giacomo T, Venuta F, Rendina EA, et al. Video-assisted thoracoscopic treatment of giant bullae associated with emphysema. Eur J Cardiothorac Surg 1999; 15: 753-756.

110 Brantigan OC. Surgical treatment of pulmonary emphysema. MD State Med J 1957; 6: 409-414.

111 Cooper JD, Trulock EP, Triantafillou AN, et al. Bilateral pneumectomy (volume reduction) for chronic obstructive pulmonary disease. J Thorac Cardiovasc Surg 1995; 109: 106-116.

112 Rationale and design of the National Emphysema Treatment Trial (NETT): A prospective randomized trial of lung volume reduction surgery. J Thorac Cardiovasc Surg 1999; 118: 518-528.

113 Fishman A, Martinez F, Naunheim K, et al. A randomized trial comparing lung-volume-reduction surgery with medical therapy for severe emphysema. N Engl J Med 2003; 348: 2059-2073.

114 Ciccone AM, Meyers BF, Guthrie TJ, et al. Long-term outcome of bilateral lung volume reduction in 250 consecutive patients with emphysema. J Thorac Cardiovasc Surg 2003; 125: 513-525. 
115 National Emphysema Treatment Trial Research Group. Patients at high risk of death after lung-volume-reduction surgery. $N$ Engl J Med 2001; 345: 1075-1083.

116 Washko GR, Fan VS, Ramsey SD, et al. The effect of lung volume reduction surgery on chronic obstructive pulmonary disease exacerbations. Am J Respir Crit Care Med 2008; 177: 164-169.

117 Snyder ML, Goss CH, Neradilek B, et al. Changes in arterial oxygenation and self-reported oxygen use after lung volume reduction surgery. Am J Respir Crit Care Med 2008; 178: 339-345.

118 Drazen JM, Epstein AM. Guidance concerning surgery for emphysema. N Engl J Med 2003; 348: 2134-2136.

119 Ware JH. The National Emphysema Treatment Trial - how strong is the evidence? N Engl J Med 2003; 348: 2055-2056.

120 Toma TP, Hopkinson NS, Polkey MI, et al. Endobronchial volume reduction: a myth or a marvel? Sem Respir Crit Care Med 2004; 25: 399-404.

121 Toma TP. Lung-volume reduction. Lancet 2001; 357: 1621.

122 Terry PB, Traystman RJ, Newball HH, et al. Collateral ventilation in man. N Engl J Med 1978; 298: 10-15.

123 Hopkinson NS, Toma TP, Hansell DM, et al. Effect of bronchoscopic lung volume reduction on dynamic hyperinflation and exercise during emphysema. Am J Respir Crit Care Med 2005; 171: 453-460.

124 Fessler HE. Collateral ventilation, the bane of bronchoscopic volume reduction. Am J Respir Crit Care Med 2005; 171: 423-424.

125 Watanabe Y, Matsuo K, Tamaoki A, et al. Bronchial occlusion with endobronchial watanabe spigot. J Bronchol 2003; 10: 264-267.

126 Macklem PT. Collateral ventilation. N Engl J Med 1978; 298: 49-50.

127 Lausberg HF, Chino K, Patterson A, et al. Bronchial fenestration improves expiratory flow in emphysematous human lungs. Ann Thorac Surg 2003; 75: 393-398.

128 Brenner M, Hanna NM, Mina-Araghi R, et al. Innovative approaches to lung volume reduction for emphysema. Chest 2004; 126: 238-248.

129 Venuta F, De Giacomo T, Rendina EA, et al. Bronchoscopic lungvolume reduction with one-way valves in patients with heterogenous emphysema. Ann Thorac Surg 2005; 79: 411-417.

130 Snell GI, Holsworth L, Borrill ZL, et al. The potential for bronchoscopic lung volume reduction using bronchial prostheses. A pilot study. Chest 2003; 124: 1073-1080.

131 Toma TP, Hopkinson NS, Hillier J, et al. Bronchoscopic volume reduction with valve implants in patients with severe emphysema. Lancet 2002; 361: 931-933.

132 Wan IY, Toma TP, Geddes DM, et al. Bronchoscopic lung volume reduction for end-stage emphysema. Report on the first 98 patients. Chest 2006; 129: 518-526.

133 De Oliveira HG, Macedo-Neto AV, John AB, et al. Transbronchoscopic pulmonary emphysema treatment. 1-month to 24-month endoscopic follow-up. Chest 2006; 130: 190-199.

134 Yim AP, Hwong TM, Lee TW, et al. Early results of endoscopic lung volume reduction for emphysema. J Thorac Cardiovasc Surg 2004; 127: 1564-1573.
135 Strange C, Herth FJ, Kovitz KL, et al. Design of the endobronchia valve for Emphysema Palliation Trial (VENT): a non-surgical method of lung volume reduction. BMC Pulmonary Medicine 2007; 7: 10.

136 Leroy S, Marquette CH. [VENT: International Study of bronchoscopic lung volume reduction as a palliative treatment for emphysema]. Rev Mal Respir 2004; 21: 1144-1152.

137 Ingenito EP, Wood DE, Utz JP. Bronchoscopic lung volume reduction in severe emphysema. Proc Am Thor Soc 2008; 5: 454-460.

138 Wood DE, McKenna RJ, Yusen RD, et al. A multicenter trial of an intrabronchial valve for treatment of severe emphysema. J Thorac Cardiovasc Surg 2007; 133: 65-73.

139 Macklem PT, Cardoso P, Snell G, et al. Airway bypass: a new treatment for emphysema. Proc Am Thor Soc 2006; 3: A726.

140 Choong CK, Macklem PT, Pierce JA, et al. Airway bypass improves the mechanical properties of explanted emphysematous lungs. Am J Resp Crit Care Med 2008; 178: 902-905.

141 Lausberg HF, Chino K, Patterson A, et al. Bronchial fenestration improves expiratory flow in emphysematous human lungs. Ann Thorac Surg 2003; 75: 393-398.

142 Ingenito EP, Berger RL, Henderson AC, et al. Bronchoscopic lung volume reduction using tissue engineering principles. Am J Respir Crit Care Med 2003; 167: 771-778.

143 Reilly J, Washko G, Pinto-Plata V, et al. Biological lung volume reduction: a new bronchoscopic therapy for advanced emphysema. Chest 2007; 131: 1108-1113.

144 Criner GJ, Pinto-Plata V, Strange C, et al. Biologic lung volume reduction (BioLVR) in advanced upper lobe emphysema: phase 2 results. Am J Resp Crit Care Med 2009; 179: 791-798.

145 Coxson HO, Fauerbach PV, Storness-Bliss C, et al. Computed tomography assessment of lung volume changes after bronchial valve treatment. Eur Respir J 2008; 32: 1443-1450.

146 Sciurba FC, Ernst A, Herth F, et al. Effect of bronchoscopically implanted endobronchial valves on lobar volumes, lung function and exercise tolerance in patients with severe emphysema. $N$ Engl J Med 2010; (In press).

147 Aljuri N, Freitag L. Validation and pilot clinical study of a new bronchoscopic method to measure collateral ventilation before endobronchial lung volume reduction. J Appl Physiol 2009; 106: 755-756

148 Toma TP, Hopkinson J, Hillier J, et al. Effect of unilateral total lobar occlusion with bronchoscopic valve implants in patients with severe heterogenous emphysema. Am J Respir Crit Care Med 2004; 165: A576.

149 Garcia-Rio F, Lores V, Mediano O, et al. Daily physical activity in patients with chronic obstructive pulmonary disease is mainly associated with dynamic hyperinflation. Am J Respir Crit Care Med 2009; 180: 506-512.

150 Roche N. Activity limitation: a major consequence of dyspnoea in COPD. Eur Respir Rev 2009; 18: 54-57. 